\title{
Sea Surface Temperature Warming Patterns and Future Vegetation Change
}

\author{
Sara A. Rauscher, ${ }^{*}$ Xiaoyan Jiang, ${ }^{+}$Allison Steiner, ${ }^{\#}$ A. PARK Williams, ${ }^{@}$ \\ D. MiCHAEL CAI, \& AND NATHAN G. MCDOWELL** \\ * Department of Geography, University of Delaware, Newark, Delaware \\ ${ }^{+}$Atmospheric Chemistry Division, National Center for Atmospheric Research, Boulder, Colorado

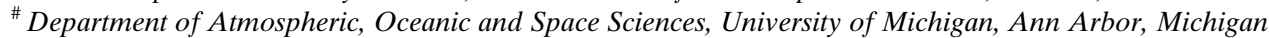 \\ ${ }^{\circledR}$ Lamont Doherty Earth Observatory, Columbia University, Palisades, New York \\ \& Intelligence and Space Research Division, Los Alamos National Laboratory, Los Alamos, New Mexico \\ ** Earth and Environmental Sciences Division, Los Alamos National Laboratory, Los Alamos, New Mexico
}

(Manuscript received 25 July 2014, in final form 22 June 2015)

\begin{abstract}
Recent modeling studies of future vegetation change suggest the potential for large-scale forest die-off in the tropics. Taken together with observational evidence of increasing tree mortality in numerous ecosystem types, there is clearly a need for projections of vegetation change. To that end, the authors have performed an ensemble of climate-vegetation experiments with the National Science Foundation-DOE Community Atmosphere Model (CAM) coupled to the Community Land Model (CAM-CLM-CN) with its dynamic vegetation model enabled (CAM-CLM-CNDV). To overcome the limitations of using a single model, the authors employ the sea surface temperature (SST) warming patterns simulated by eight different models from the Coupled Model Intercomparison Program phase 3 (CMIP3) as boundary conditions. Since the SST warming pattern in part dictates how precipitation may change in the future, in this way a range of future vegetation-climate trajectories can be produced.

On an annual average basis, this study's CAM-CLM-CN simulations do not produce as large a spread in projected precipitation as the original CMIP3 archive. These differences are due to the tendency of CAMCLM-CN to increase tropical precipitation under a global warming scenario, although this response is modulated by the SST warming patterns imposed. However, the CAM-CLM-CN simulations reproduce the enhanced dry season in the tropics simulated by CMIP3. These simulations show longer fire seasons and increases in fractional area burned. In one ensemble member, extreme droughts over tropical South America lead to fires that remove vegetation cover in the eastern Amazon, suggesting that large-scale die-offs are an unlikely but still possible event.
\end{abstract}

\section{Introduction}

Terrestrial vegetation is an important component of the climate system: vegetation alters the physical properties of the land surface, affecting how much solar radiation is received at the surface as well as how that energy is partitioned. Further, forests provide an important sink for anthropogenic carbon dioxide $\left(\mathrm{CO}_{2}\right)$ emissions in part because of the fertilization effect in which higher levels of atmospheric $\mathrm{CO}_{2}$ increase photosynthesis and water use

Corresponding author address: Sara A. Rauscher, Dept. of Geography, University of Delaware, 219 Pearson Hall, Newark, DE 19716.

E-mail: rauscher@udel.edu efficiency by plants (e.g., Notaro et al. 2007; Ballantyne et al. 2012). Despite these potential beneficial effects of increasing $\mathrm{CO}_{2}$, there is recent evidence of increasing tree mortality around the world in numerous ecosystem types (Allen et al. 2010). These widespread observations of mortality events suggest that climate change is contributing to increasing forest death, which may eventually lead to a tipping point where climate changes rapidly or substantially enough to initiate large-scale die-offs. Warming could accelerate through the reduction of the biomass carbon sink.

As a result of the interplay between the two effects of $\mathrm{CO}_{2}$, the fertilization effect and climate change itself, it is unclear how future climate and vegetation trajectories will unfold. In the tropics, the relative importance of two 
competing climate responses to increasing greenhouse gases ${ }^{1}$ - a local ("bottom up") response and a remote ("top down") response (Giannini 2010; Seth et al. 2011, 2013) — is likely an important arbiter of how climate will change, with important implications for how vegetation will respond. In the local response, increases in net surface radiation lead to increases in evaporation and low-level moist static energy, driving increased precipitation and moisture convergence. In the remote response, the rising heat content of the ocean and higher sea surface temperatures (SSTs) result in nearly uniform warming in the upper troposphere (Sobel et al. 2001), increasing stability. Precipitation is reduced over tropical land areas where there is insufficient moist static energy to overcome this enhanced stability (Chou and Neelin 2004; Chou et al. 2009; Giannini 2010). Subsequent reductions in precipitation recycling promote further drying. The remote mechanism can operate in space, with precipitation decreasing on the subtropical margins (Chou and Neelin 2004; Chou et al. 2009) but also in time with precipitation decreasing in the winter or dry season into the spring (Biasutti and Sobel 2009; Seth et al. 2010, 2011, 2013).

These mechanisms can also operate over the oceans via the spatial pattern of SST warming; this is known as the "warm get wetter" pattern (Xie et al. 2010). Areas where SSTs increase more relative to the mean tropical warming regions can more easily sustain convection despite warming of the free troposphere. These regions with greater warming have greater instability and thus become wetter in future climate projections (Xie et al. 2010). Therefore, in this warm get wetter mechanism, the pattern of SST warming controls where precipitation will increase the most (Rauscher et al. 2008, 2011; Xie et al. 2010; Ma and Xie 2013). Additionally, these precipitation changes may affect other regions remotely through teleconnections (Huang et al. 2013).

The influence of SST warming patterns is evident in modeling studies of climate and vegetation change, with perhaps the best example being simulated die-off over the Amazon basin. In a widely cited study, Cox et al. (2000) used the Hadley Centre Coupled AtmosphereOcean Model version 3 (HadCM3) coupled to an ocean carbon cycle model and a dynamic vegetation model to simulate future climate and ecosystem change over the Amazon. In their simulation, a complete die-off of the Amazon forest begins in the middle of the twenty-first century. This simulated die-off was the result of severe droughts due to an El Niño-like warming over the central-eastern Pacific that altered the atmospheric

\footnotetext{
${ }^{1}$ See also Fig. 1 in Seth et al. (2013).
}

\begin{tabular}{llcl}
\hline Ensemble Name & $\begin{array}{l}\text { Control Run } \\
\mathbf{1 9 9 0 - 2 0 0 5}\end{array}$ & $\begin{array}{c}\text { Member } \\
\text { Number }\end{array}$ & $\begin{array}{l}\text { A2 Future } \\
\mathbf{2 0 0 6}-2100\end{array}$ \\
\hline CAM-CLM-CN & Observed SSTs & 1 & CCSM3 SSTs \\
No dynamic vegetation & & 2 & CNRM-CM3 SSTs \\
& & 3 & ECHAM5 SSTs \\
& & 4 & GFDL-CM21 SSTs \\
& & 5 & GISS-ER SSTs \\
& 6 & HadCM3 SSTs \\
& & 7 & HadGEM1 SSTs \\
\hline CAM-CLM-CNDV & Observed SSTs & 1 & MRI-CGCM2.3a SSTs \\
With dynamic & & 2 & CNRM3 SSTs \\
vegetation & & 3 & ECHAM5 SSTs \\
& & 4 & GFDL-CM21 SSTs \\
& & 5 & GISS-ER SSTs \\
& 6 & HadCM3 SSTs \\
& & 7 & HadGEM1 SSTs \\
& & 8 & MRI-CGCM2.3a SSTs \\
\hline
\end{tabular}

FIG. 1. Experimental design.

circulation such that large-scale descent and a reduction in precipitation occurred over the Amazon (Cox et al. 2000, 2004; Li et al. 2006). HadCM3 also simulated a meridional gradient in the warming of the tropical Atlantic that contributed to drying (Harris et al. 2008).

However, all model simulations of future climate do not display this same SST warming pattern, and not all models simulate drying over the Amazon ( $\mathrm{Li}$ et al. 2006). In fact, of all the models in the Coupled Model Intercomparison Project phase 3 (CMIP3; Meehl et al. 2007), HadCM3 simulates the largest future decrease in precipitation over the Amazon ( $\mathrm{Li}$ et al. 2006). Therefore, we must ask, how probable and how uncertain are these HadCM3 results over tropical South America? More generally, how probable is large-scale vegetation change in the tropics as a whole? Since none of the scenario simulations in the CMIP3 database (and only a few in CMIP5) were run with fully interactive carbon cycles or dynamic vegetation, a large fully interactive carbon-climate multimodel ensemble is not possible.

Here we create projections of future vegetation and climate change over the tropics using a single model, the National Science Foundation (NSF)-DOE Community Earth System Model (CESM1.0; Gent et al. 2011). We mimic a multimodel atmosphere-vegetation ensemble through the use of SST projections from eight different coupled climate models in CMIP3 (Meehl et al. 2007) as boundary conditions. In this way, we can produce multiple realizations of twenty-first-century climate under a medium-high emissions scenario (SRES A2; IPCC 2000) using the interactive land and atmosphere components of CESM. Since previous studies have reported the potential for the die-off of the Amazon, we focus our efforts on tropical South America while also considering the tropics as a whole. In contrast to recent studies that 

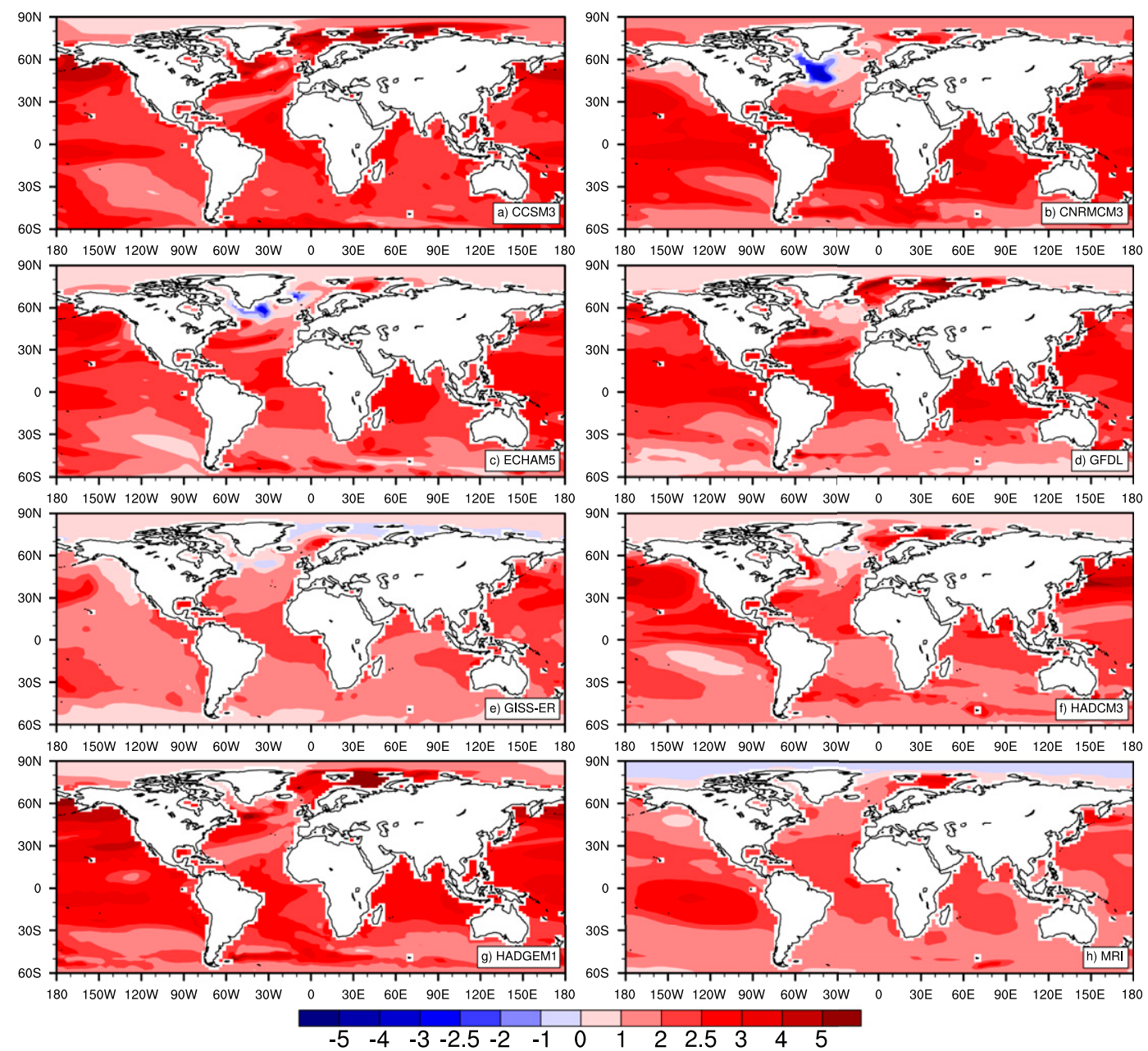

FIG. 2. Bias-corrected annual average SST anomalies $\left({ }^{\circ} \mathrm{C}\right)$ for the end of the twenty-first century (2070-99) vs the end of the twentieth century (1970-99) from CMIP3 simulations (a) CCSM3, (b) CNRM-CM3, (c) ECHAM5, (d) GFDL, (e) GISS-ER, (f) HadCM3, (g) HadGEM1, and (h) MRI.

have utilized offline simulations driven with biascorrected data from CMIP3 models (e.g., Huntingford et al. 2013), we ran our simulations with full interaction between the land and atmosphere. Because we are using a single model, we focus our analysis on the effects of the differences in the climate drivers rather than on the effects of physiological parameterizations. Importantly, we examine the ability of our single-model ensemble to capture the spread of the original CMIP3 multimodel ensemble.

Section 2 describes the models and experimental design. Section 3 presents an analysis of the control simulation. The ability of our single model ensemble to capture the range of responses in the full CMIP3 ensemble is discussed in section 4 . The simulated changes in tropical vegetation are discussed in section $4 \mathrm{~b}$. Finally, discussion and conclusions are presented in section 5.

\section{Model, data, and experimental design}

\section{a. Model}

For our simulations we use the atmosphere and land components of the NSF-DOE Community Earth System Model (CESM) (Gent et al. 2011), the most recent version of the Community Climate System Model (CCSM). The atmospheric component of CESM is the Community Atmosphere Model (CAM); we use the finite volume (FV) dynamical core and CAM4 physics with 26 vertical levels (Neale et al. 2010). The spatial resolution of the model is $1.9^{\circ}$ latitude by $2.5^{\circ}$ longitude. This medium horizontal resolution was chosen because of the need to perform 16 ensemble members, including 8 members with dynamic vegetation. Exchanges of heat, moisture, and momentum fluxes between the land and the atmosphere are simulated by the Community Land 


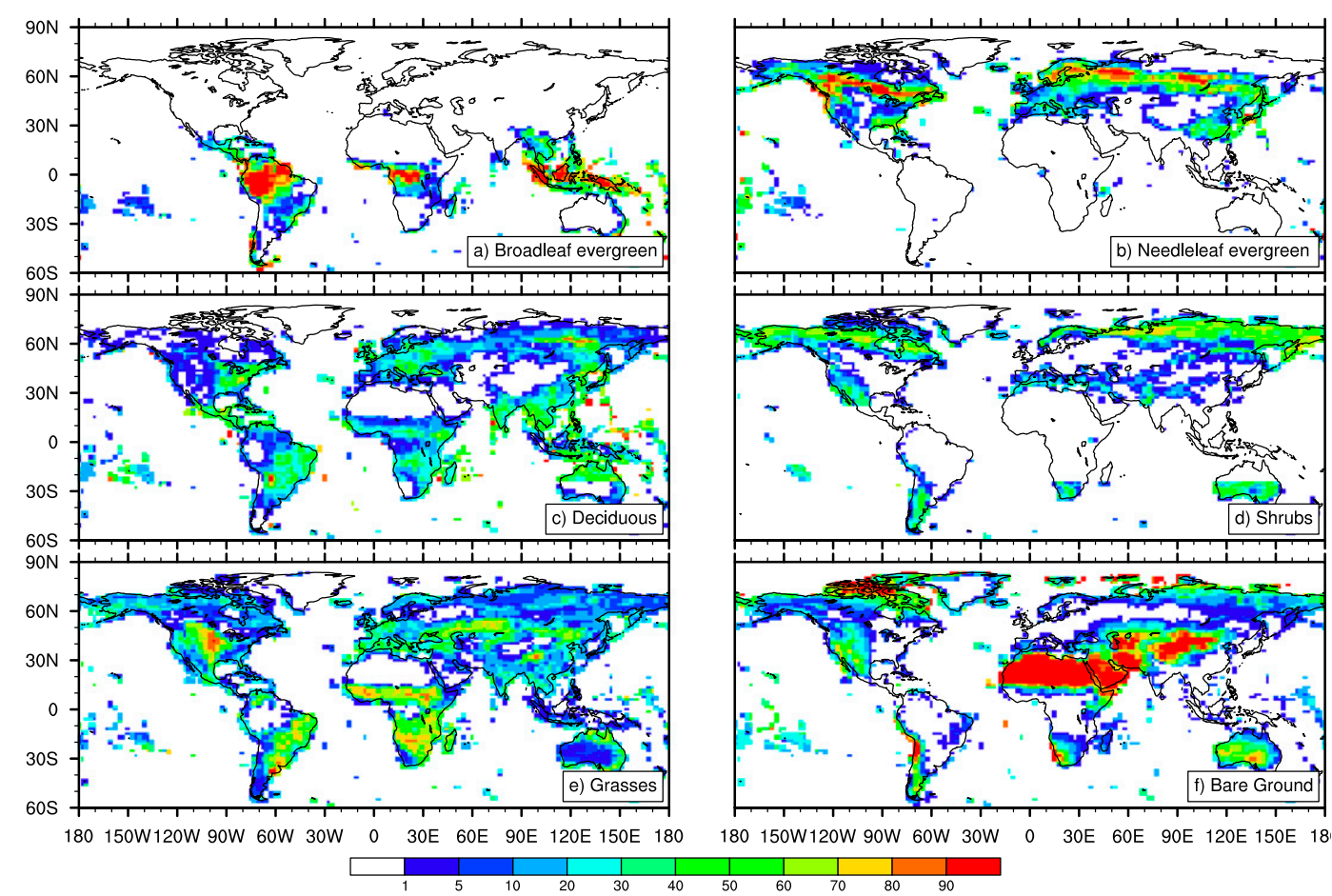

FIG. 3. Observed plant function types (\% cover) used in CAM-CLM-CN simulations: (a) broadleaf evergreen trees, (b) needleleaf evergreen trees, (c) deciduous trees, (d) shrubs, (e) grasses, and (f) bare ground.

Model (CLM), version 4.0. In CLM, vegetation coverage is described in each grid cell by fractional areas of plant functional types (PFTs). There are 17 PFTs, including bare ground, 11 tree PFTs, 3 grass PFTs, and 2 crop PFTs; however, crop types and historical transient land-use change are not used when the dynamic vegetation model is enabled (Lawrence et al. 2011). CLM includes a carbon-nitrogen $(\mathrm{CN})$ biogeochemical model that controls carbon and nitrogen dynamics (Thornton et al. 2007) and predicts vegetation, litter, soil carbon and nitrogen states, and vegetation phenology. We also utilize the dynamic vegetation model (CNDV), which is based on the Lund-Potsdam-Jena (LPJ) model (Sitch et al. 2003). In our simulations, the interaction between the land and atmosphere components is two way, unlike previous studies performed to evaluate the basic performance of CLM in CESM (e.g., Gotangco Castillo et al. 2012).

We performed two ensembles: one ensemble with CAM and CLM with $\mathrm{CN}$ and the dynamic vegetation model enabled (CAM-CLM-CNDV) (Levis et al. 2004; Gotangco Castillo et al. 2012) and one ensemble with no dynamic vegetation (CAM-CLM-CN). Carbon cycle dynamics are controlled by CAM-CLM-CN in both sets of simulations. The main differences between CAMCLM-CN and CAM-CLM-CNDV are the biogeography as represented by the distribution of PFTs and the parameterization of mortality processes (Gotangco Castillo et al. 2012). For CAM-CLM-CN, vegetation PFTs are prescribed from satellite data and cannot change through time. In CAM-CLM-CNDV, PFTs are established through time, and vegetation change is represented by a change in the fractional PFT coverage of a grid cell at the end of each simulation year (Sitch et al. 2003). PFT types can change in CAM-CLM-CNDV because of 20-yr climate envelopes based on temperature and precipitation limits as well as because of mortality mechanisms. These mortality mechanisms differ between CAM-CLM-CN and CAM-CLM-CNDV: CAM-CLMCNDV calculates mortality due to heat stress (based on an accumulation of growing degree days), fire, and growth efficiency, while CAM-CLM-CN uses a flat $2 \%$ mortality rate. While PFT type cannot change in CAM-CLM-CN simulations, vegetation characteristics such as leaf area index can still change because of climate change or interannual variability.

Because the fire module in CLM is important to the results discussed in section $4 \mathrm{~b}$, it is described in more detail here. In both CAM-CLM-CN and CAM-CLMCNDV, fire is a prognostic algorithm based on Thonicke et al.'s (2001) intermediate-complexity Global Fire Model (Glob-FIRM), which depends on surface fuel availability and near-surface soil moisture conditions (Oleson et al. 2010); however, ignition source 


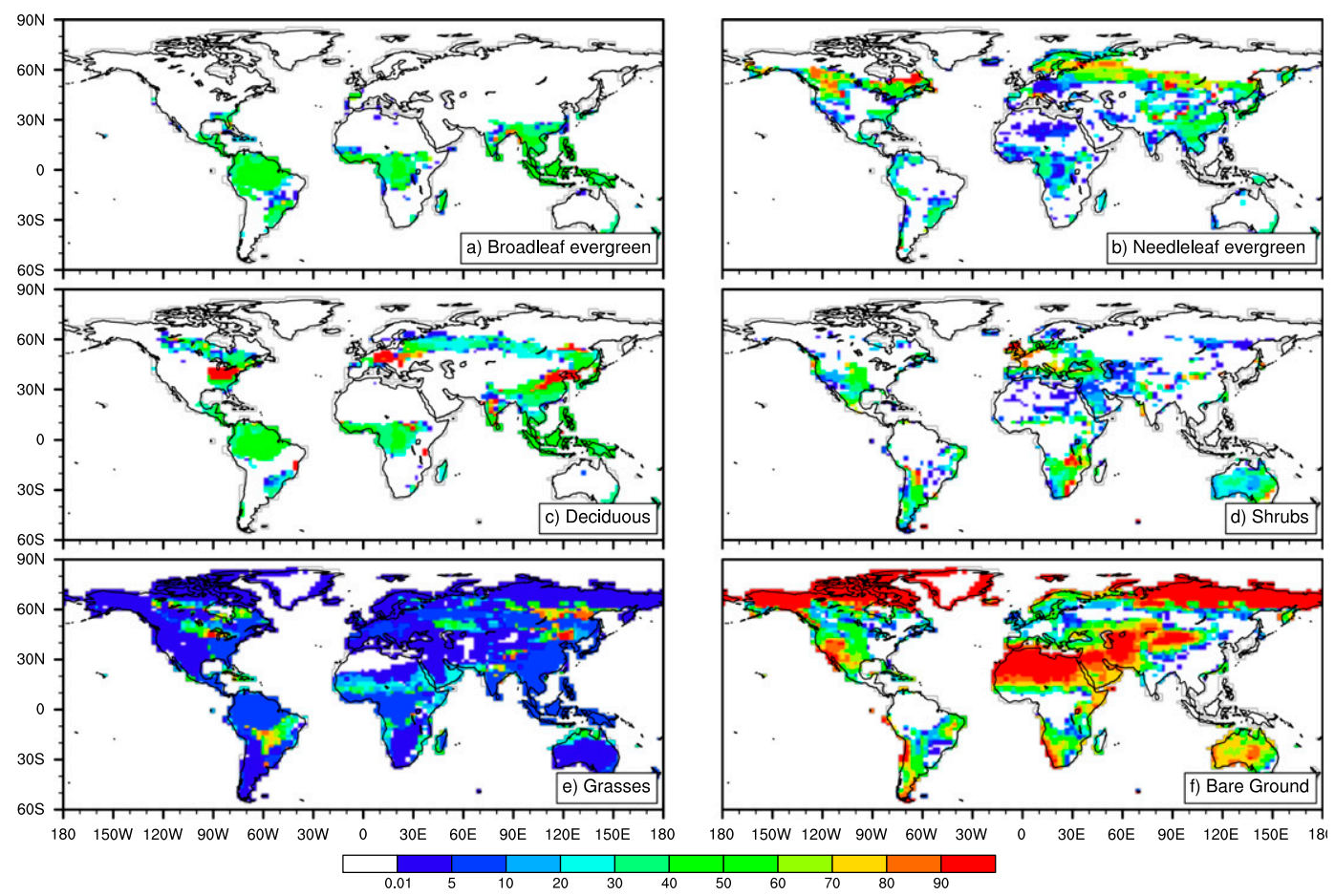

FIG. 4. Simulated plant functional types (average over 1970-99; \% cover) in CAM-CLM-CNDV simulations: (a) broadleaf evergreen trees, (b) needleleaf evergreen trees, (c) deciduous trees, (d) shrubs, (e) grasses, and (f) bare ground.

availability and the effects of wind speed on fire are not considered ( $\mathrm{Li}$ et al. 2012). As with the PFT changes, the effects of fire are applied at the end of each simulation year to each grid cell. The effect of fire depends on fire season length in days, which is dependent on subhourly fire probability. This in turn is a function of the ratio of volumetric soil moisture in the top $0.5 \mathrm{~m}$ of soil water to the saturation soil water. Fire season length and fuel control the area affected by fire. A difference between CAM-CLM-CN and CAM-CLM-CNDV is that with CNDV fire can affect PFT coverage by removing a number of individuals as a function of the area burned from the PFT population. If enough individuals are removed, PFT cover is reduced to zero (i.e., the land cover changes to bare ground).

\section{b. Data}

To evaluate the control simulation, we use gridded land-only observations from the University of Delaware dataset, version 3.02 (Willmott and Matsuura 1995, 2001). Monthly 2-m temperature data are available at $0.5^{\circ}$ resolution for the 1900-2010 timeframe; here we use an average from 1970 to 1999 . For evaluation of precipitation, we use the Climate Prediction Center Merged Analysis of Precipitation (CMAP; Xie and Arkin 1996) dataset and the Climate Anomaly Monitoring System
(CAMS) and OLR Precipitation Index (OPI; Janowiak and Xie 1999). The CMAP dataset is a blended product of global satellite and gauge data on a $2.5^{\circ} \times 2.5^{\circ}$ latitude-longitude grid, approximately the same as the CAM-CLM-CN simulations. We use the period 19792008, since the dataset is available from 1979 onward. CAMS-OPI is a precipitation estimation technique that produces real-time monthly analyses of global precipitation. Rain gauge observations (CAMS data) are combined with precipitation estimates from a satellite algorithm (OPI). The analyses are on a $2.5^{\circ} \times 2.5^{\circ}$ latitude-longitude grid, are updated each month, and are available for 1979-present.

\section{c. Experiment design}

As discussed above, recent numerical experiments suggest that future SST patterns may play an important role in shaping how precipitation may change in a warmer world (Rauscher et al. 2008, 2011; Xie et al. 2010; Ma and Xie 2013). For example, simulations that show warming in the eastern tropical Pacific and a meridional gradient in warming in the tropical Atlantic tend to reduce precipitation over the Amazon. Models that do not have a similar warming pattern do not simulate reductions in precipitation over the Amazon ( $\mathrm{Li}$ et al. 2006). To simulate a range of potential future 

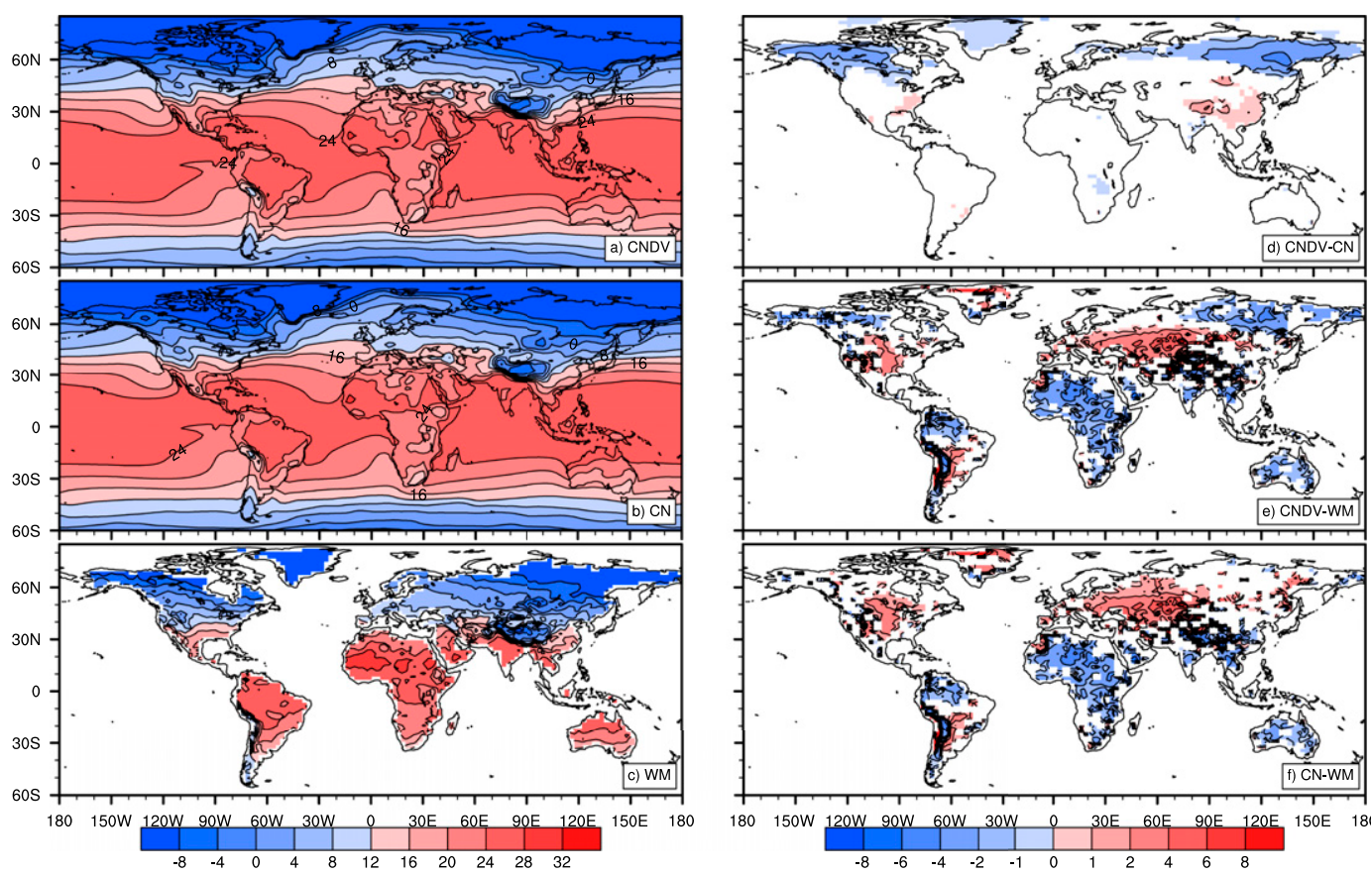

FIG. 5. Modeled and observed annual average temperature (1970-99; $\left.{ }^{\circ} \mathrm{C}\right)$ for (a) CAM-CLM-CNDV control simulation, (b) CAM-CLM-CN control simulation, (c) WM observations, and differences (d) CAM-CLM-CNDV CAM-CLM-CN, (e) CAM-CLM-CNDV - WM, and (f) CAM-CLM-CN - WM. For (d)-(f), only significant differences are shown.

climates while using a single model, we used SST projections from eight different fully coupled climate models from CMIP3 (Meehl et al. 2007) as boundary conditions for our simulations.

The spinup procedures used for the simulation are described in full by Jiang et al. (2013); we summarize here for brevity. We performed a 155-yr coupled atmosphere-land (CAM-CLM-CNDV) spinup simulation. Initial conditions for this 155 -yr coupled simulation were provided by a 200 -yr offline CLM-CNDV simulation that cycled through the 1948-2004 observed atmospheric forcing (Qian et al. 2006) and started from the end of a twentieth-century CLM-CN transient simulation. Net ecosystem exchange (NEE) was near zero by the end of the twentieth-century control simulation.

Two ensembles were performed, each with one historical control simulation (1900-2005) and eight future scenario simulations (2005-99), as illustrated in Fig. 1. The historical control simulation in each ensemble is forced by observed SSTs with the land model initial conditions taken from the end of the spinup run. The results from the end of the single historical simulation were used to initialize the eight future scenario simulations in which SST projections from different CMIP3 models were bias corrected based on observed SSTs (Hurrell et al. 2008). These eight GCMs include the NCAR CCSM3, CNRMCM3, MPI ECHAM5, GFDL CM2.1, GISS-ER, UKMO
HADCM3, UKMO HadGEM1, and MRI-CGCM2.3.2a as shown in Fig. 1 and Fig. 2. Selection of the different models is described in Jiang et al. (2013). Throughout the text we refer to these CMIP3 simulations as the "parent" CMIP3 simulations.

The two ensembles of one control simulation and eight scenario simulations differ in the use of the dynamic vegetation model. For the first ensemble, we used CAMCLM coupled with dynamic vegetation enabled. In the second ensemble, the dynamic vegetation was turned off. To be consistent with the future SST projections, greenhouse gas emissions from the IPCC SRES A2 emissions scenario are used as forcing (IPCC 2000). Aerosol concentrations and deposition rates in all simulations were held constant at year-2000 levels. Prescribed transient $\mathrm{CO}_{2}$ and nitrogen deposition rates (Lamarque et al. 2010) were employed for the historical and future-year simulations. Unless otherwise noted, averages representing the late twenty-first century (2070-99) and the twentieth century (1970-99) are compared to assess the future changes relative to the present.

\section{Results: Control simulations}

We first examine the vegetation distribution simulated in our historical control simulation with dynamic vegetation on. Overall, our control simulation results 


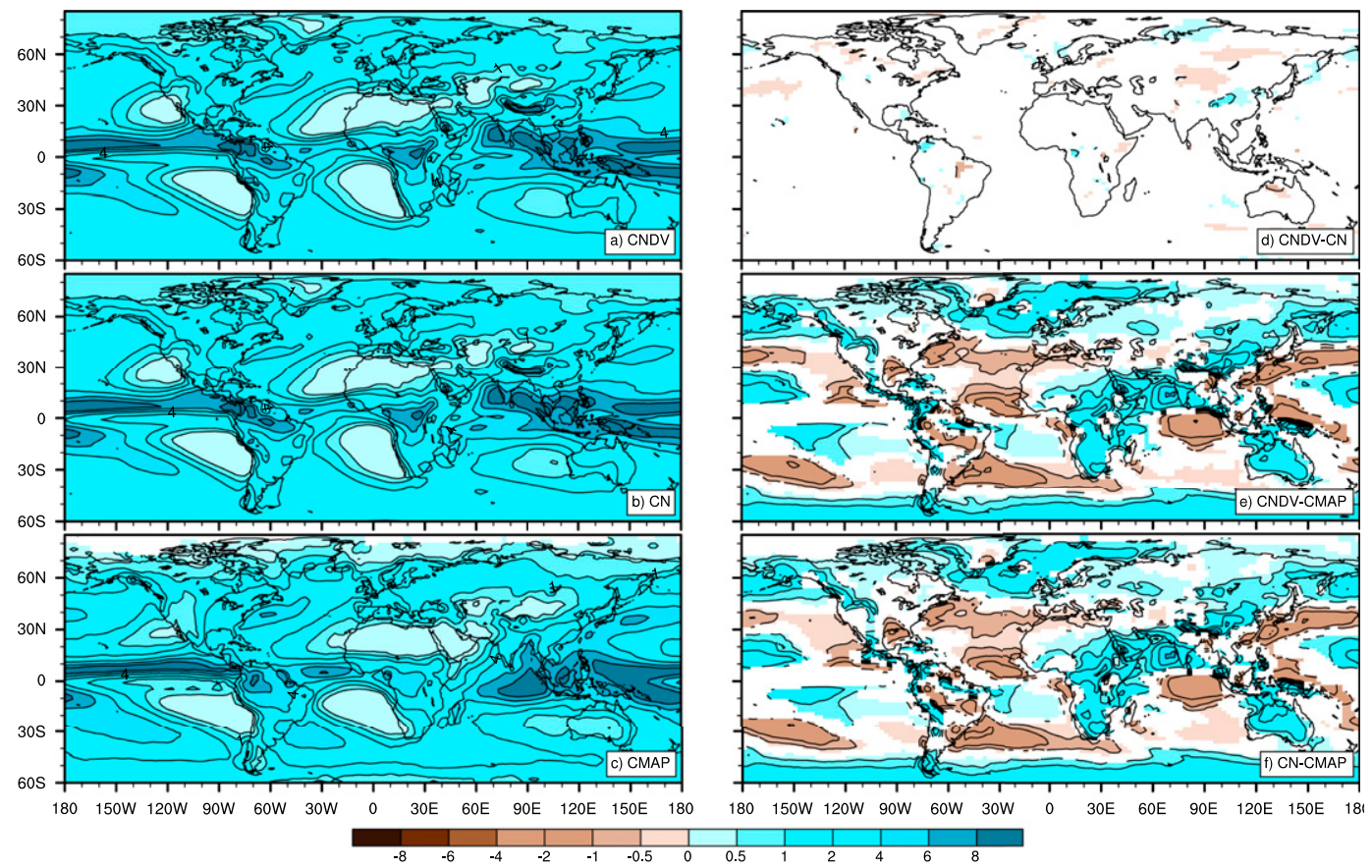

FIG. 6. Modeled and observed annual average precipitation (1970-99; $\mathrm{mm} \mathrm{day}^{-1}$ ) for (a) CAM-CLM-CNDV control simulation, (b) CAM-CLM-CN control simulation, (c) CMAP observations, and differences (d) CAMCLM-CNDV - CAM-CLM-CN, (e) CAM-CLM-CNDV - CMAP, and (f) CAM-CLM-CN - CMAP. For (d)-(f), only significant differences are shown.

are very similar to the results obtained in a previous evaluation of CLM-CNDV by Gotangco Castillo et al. (2012, their Fig. 2). The main difference between the simulations of Gotangco Castillo et al. (2012) and those presented here is that the former utilized a one-way forcing of CLM-CNDV by atmospheric data produced using CAM, whereas our simulations are interactive between the atmosphere and land surface.

Figures 3a-f show the observed distribution of PFTs derived from MODIS satellite data that are used within the model when prescribing "natural" vegetation cover (i.e., the vegetation distribution that would be used in the CAM-CLM-CN configuration when the dynamic vegetation is turned off). Figures $4 \mathrm{a}-\mathrm{f}$ show the PFTs produced in the CAM-CLM-CNDV control simulation. The spatial distribution of broadleaf evergreen trees agrees fairly well with the satellite-derived PFTs over tropical regions; that is, broadleaf evergreens are found over central America and the Amazon, central Africa, southern Asia, Southeast Asia, and parts of Australia and New Zealand. Relative fractional coverage is underestimated, however. This deficiency is compensated for by increased deciduous tree coverage. For example, while the Amazon is covered by more than $90 \%$ broadleaf evergreen according to the satellite data, in
CAM-CLM-CNDV it has approximately $45 \%$ broadleaf evergreen and $45 \%$ deciduous trees. In CAMCLM-CNDV there is no mandatory senescence period, so the deciduous trees are able to "compete" in this region (Gotangco Castillo et al. 2012). Grass (C3 and C4), shrub, and bare-ground PFTs are shown in Figs. 3d,e and Figs. 4d,e. Over the Southern Hemisphere the simulation agrees more closely with observations, with shrub cover found over southern South America, southern Africa, and Australia. Grasses are underestimated almost everywhere, whereas bare ground is overestimated. Again, these simulations compare well with the established performance of CNDV and its parent DGVM, LPJ (Notaro et al. 2007).

We can compare this CAM-CLM-CNDV simulation with our control CAM-CLM-CN simulation to determine the effect of these differences in vegetation cover (dynamic versus prescribed, respectively) on the simulation of twentieth-century climate (Figs. 5 and 6). Comparing averages for model years 1970-99, there are no statistically significant differences in temperature over most of the tropics. Precipitation differences between the two simulations are small, less than $0.5 \mathrm{~mm} \mathrm{day}^{-1}$. Although the Amazon tree cover is spuriously split between broadleaf evergreen and deciduous tree types in the CAM-CLM-CNDV simulation as noted above, only a 

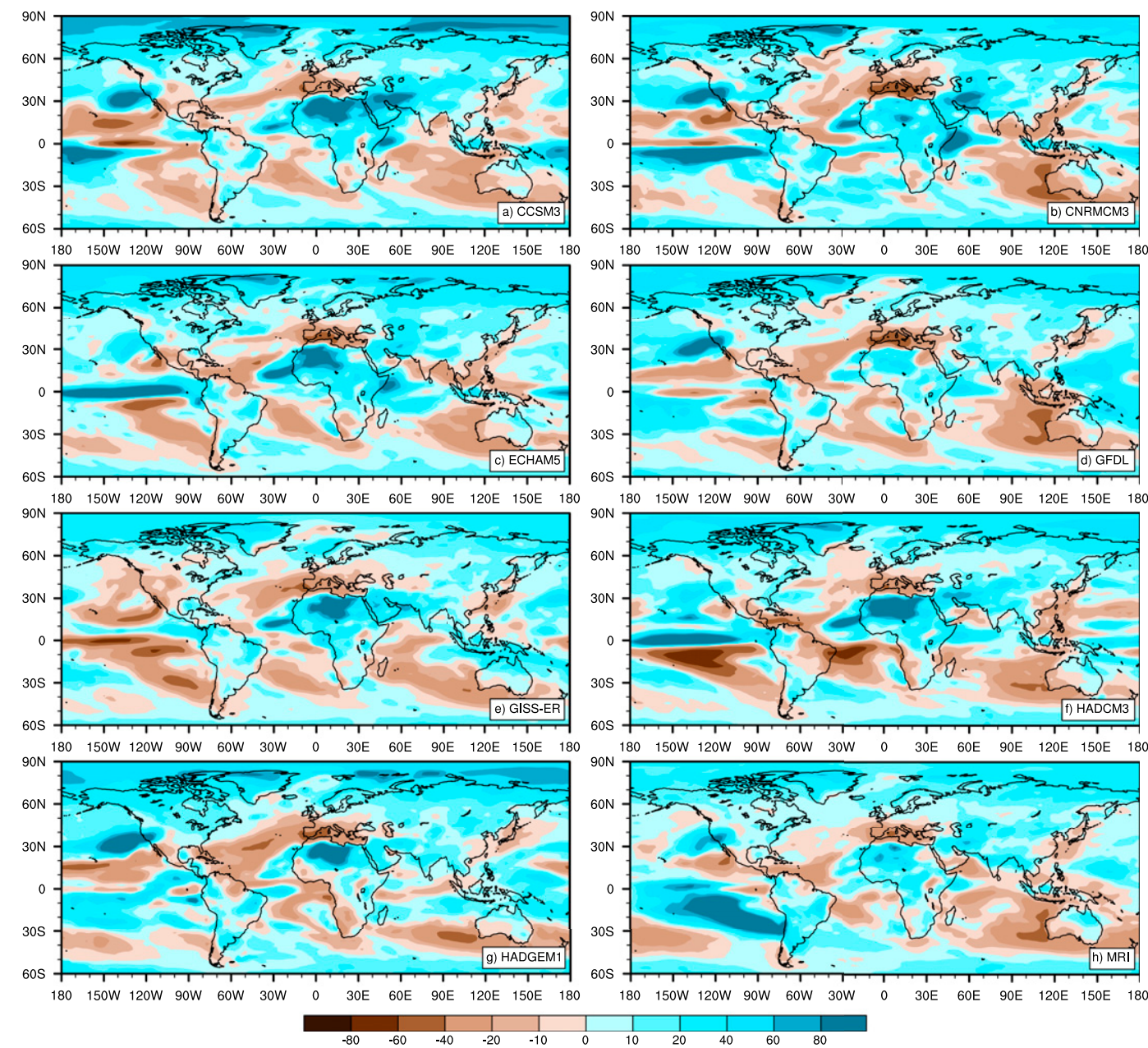

FIG. 7. Annual average precipitation change (\%) for end of the twenty-first century (2070-99) vs end of the twentieth century (1970-99) for CAM-CLM-CN simulations driven by SSTs from (a) CCSM3, (b) CNRM-CM3, (c) ECHAM5, (d) GFDL, (e) GISS-ER, (f) HadCM3, (g) HadGEM1, and (h) MRI.

small region over eastern Brazil shows lower precipitation in CAM-CLM-CNDV compared to CAM-CLM-CN.

\section{Results: Future projections}

\section{a. Reproducibility of CMIP3 ensemble}

As shown in Fig. 2, the long-term annual average of the SST change patterns used to drive the CAM-CLM$\mathrm{CN}$ and CAM-CLM-CNDV simulations varies between the CMIP3 models. Some models show El Niño-like warming in the tropical eastern Pacific (e.g., GFDL, HadCM3, CNRM) and others do not (GISS-ER, ECHAM5). To see how our simulations responded to these eight different SST warming patterns compared to their parent CMIP3 simulations, we compare the precipitation changes between the end of the twenty-first century (2070-99) to the end of the twentieth century
(1970-99) in our simulations with the parent CMIP3 simulations. Figure 7 shows the percent precipitation differences for the CAM-CLM-CN simulations for comparison with the parent CMIP3 simulations (Fig. 8). There are general similarities between the CAM-CLM$\mathrm{CN}$ simulations and their parent CMIP3 simulations that are typical of almost all future climate change simulations. For example, drying is found in the subtropics, and the midlatitude storm tracks shift poleward. Over the oceans, the precipitation changes tend to follow departures from the zonal mean SST warming (Ma and Xie 2013). Where SSTs warm more than the zonal mean, precipitation increases, and where they warm less, precipitation decreases. These differences in warming pattern can be large and account for a substantial portion (up to one-third) of intermodel spread in future precipitation projections (Ma and Xie 2013). For example, the tropical North Atlantic shows a warming minimum 

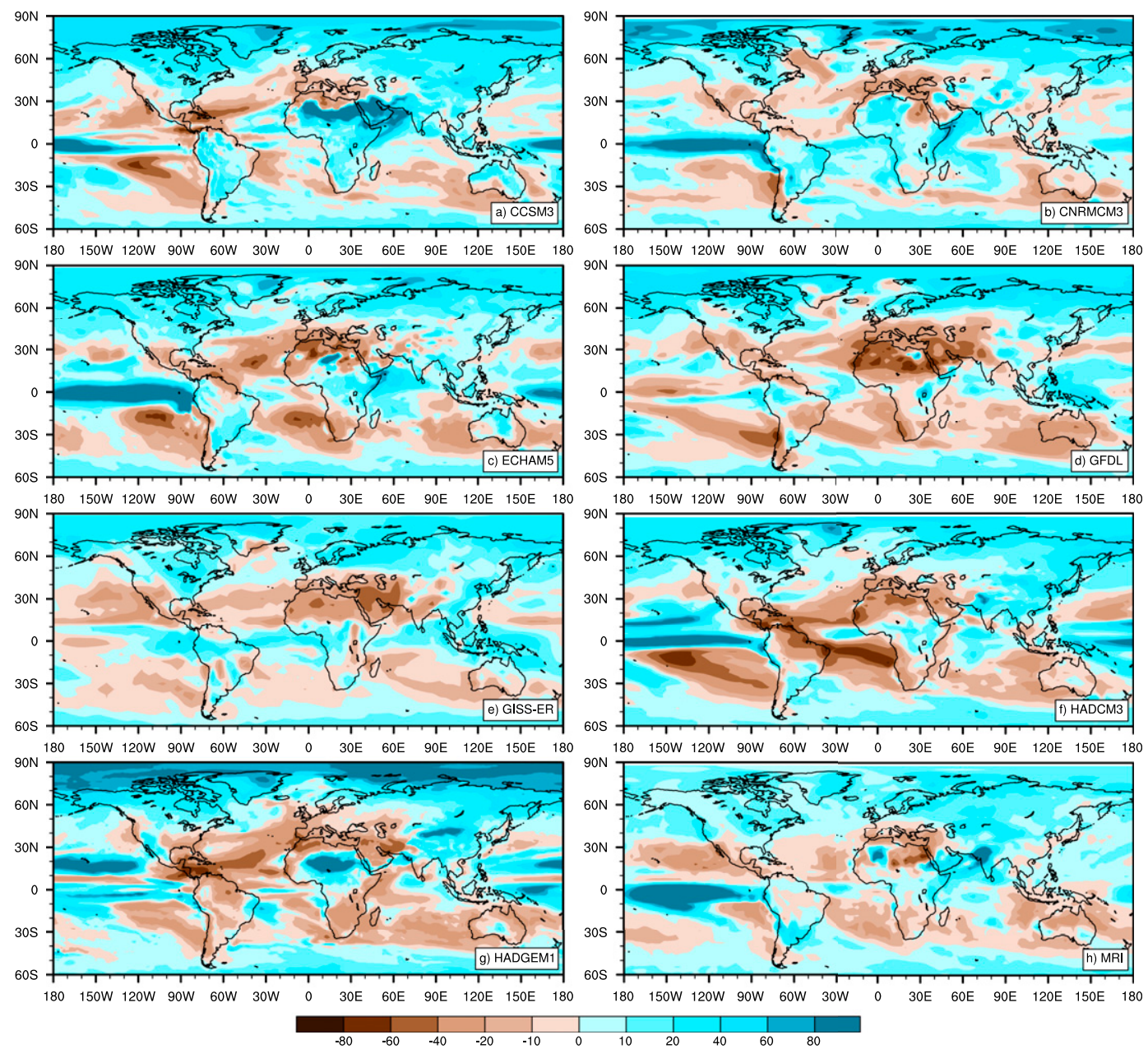

FIG. 8. Annual average precipitation change (\%) for end of the twenty-first century (2070-99) vs end of the twentieth century (1970-99) for CMIP3 simulations (a) CCSM3, (b) CNRM-CM3, (c) ECHAM5, (d) GFDL, (e) GISS-ER, (f) HadCM3, (g) HadGEM1, and (h) MRI.

in most CMIP3 projections of future SSTs (Fig. 2; CCSM3 and HadCM3 show this clearly) (Leloup and Clement 2009), which is associated with lower projected precipitation in the region (Rauscher et al. 2011).

Over tropical South America $\left(15^{\circ} \mathrm{S}-5^{\circ} \mathrm{N}, 70^{\circ}-45^{\circ} \mathrm{W}\right)$, the parent CMIP3 simulations indicate a range of possible changes in precipitation, from wetter conditions (CCSM3) to drier conditions (HadCM3). While the exact spatial distribution of the patterns differ, the sign of the precipitation change (future compared to twentieth century) between the parent CMIP3 simulations and our CAM-CLM-CN simulations is fairly consistent and seems to scale between the CMIP3 and CAM-CLM-CN simulations. This is demonstrated in Fig. 9, which shows a simple scatterplot of the CAM-CLM-CN precipitation anomalies (annual average future minus present) averaged over tropical South America compared to their CMIP3 parent anomalies (blue circles). With one exception, positive (negative) anomalies in the parent CMIP3 simulation are translated to positive (negative) anomalies in our CAM-CLM-CN simulations. However, there is a shift such that the CAM-CLM-CN simulations are wetter overall in the future than are their CMIP3 parents. To confirm this relationship, we also examined another tropical region, western and central Africa $\left(0^{\circ}-12^{\circ} \mathrm{N}, 15^{\circ} \mathrm{W}-15^{\circ} \mathrm{E}\right)$. The parent CMIP3 simulations indicate a range of possible changes in precipitation, from wetter conditions (CCSM3) to drier conditions (GFDL). All of our CAM-CLM-CN simulations indicate wetter conditions in the future (cf. Fig. 7 to Fig. 8). However, the degree to which our CAM-CLM-CN simulations become wetter in the future is modulated by the applied CMIP3 SSTs. This is demonstrated by the red circles in Fig. 9, which show that a wetter future in the CMIP3 simulations translates to a much wetter future in the CAM-CLM-CN simulations. A drier future in the 


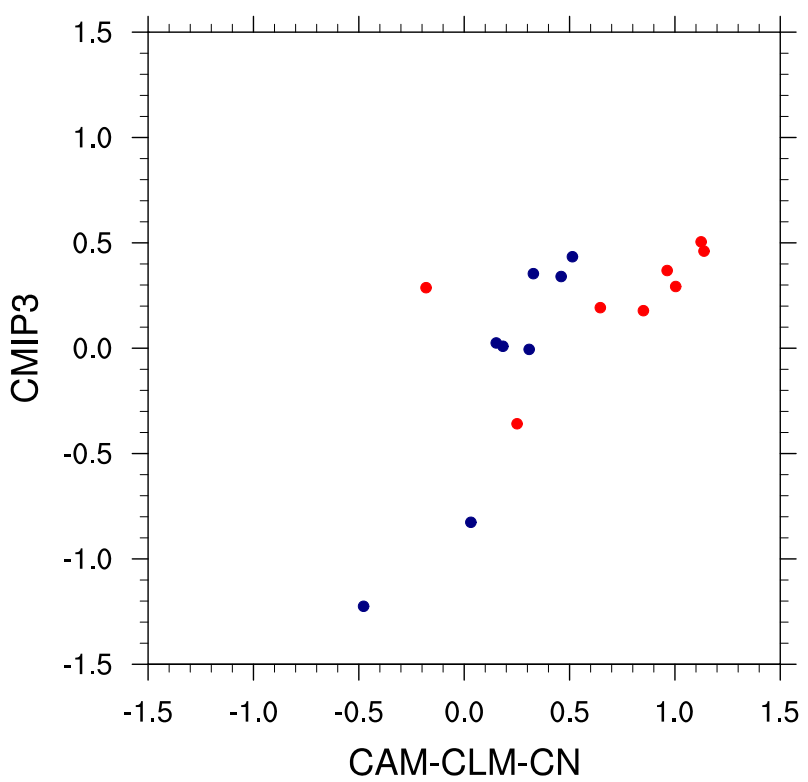

FIG. 9. Scatterplot of CAM-CLM-CN precipitation anomalies (annual average future minus present; $\mathrm{mm} \mathrm{day}^{-1}$ ) compared to their CMIP3 parent anomalies. Tropical South America is shown in blue $\left(15^{\circ} \mathrm{S}-5^{\circ} \mathrm{N}, 70^{\circ}-45^{\circ} \mathrm{W}\right)$ and western and central Africa $\left(0^{\circ}-\right.$ $\left.12^{\circ} \mathrm{N}, 15^{\circ} \mathrm{W}-15^{\circ} \mathrm{E}\right)$ is shown in red.

CMIP3 simulations translates to a wetter future in the CAM-CLM-CN simulations, but to a lesser extent.

When considering the tropics as a whole $\left(20^{\circ} \mathrm{S}-20^{\circ} \mathrm{N}\right)$, the ensemble average of our CAM-CLM-CN simulations shows increasing precipitation through the twenty-first century in the annual average (Fig. 10a, solid black line), whereas the parent CMIP3 ensemble indicates little trend (Fig. 10a, solid blue line). However, there are important seasonal variations to these tendencies. Our simulations do capture the drying during the Southern Hemisphere dry season (May-September) (Fig. 10b; cf. solid black line to solid blue line), which is part of an intensification of the annual cycle (wetter wet season and drier dry season) in future climate projections that is stronger in the Southern Hemisphere (Tan et al. 2008; Seth et al. 2011, 2013). Overall, these results indicate that CAMCLM-CN does respond to the imposed SST patterns, but it is heavily modulated by the tendency of CAM-CLM$\mathrm{CN}$ to favor a wetter future in tropical regions. Nonetheless, the wintertime drying that is critical for fire occurrence and vegetation change in the real world (e.g., Marengo et al. 2008; Lewis et al. 2011) is present, and this drying over tropical South America does prompt some interesting vegetation responses. These are outlined in section $4 b(1)$. We will return to possible reasons for CAM-CLM-CN's wet future projections in section $4 \mathrm{~b}(2)$.

\section{b. Projected vegetation change}

\section{1) TROPICS}

Figure 11 shows the ensemble mean changes in PFTs for 2070-99 compared to 1970-99 in the CAM-CLMCNDV experiments. In tropical regions, there are modest increases in the coverage of the broadleaf evergreen PFT.
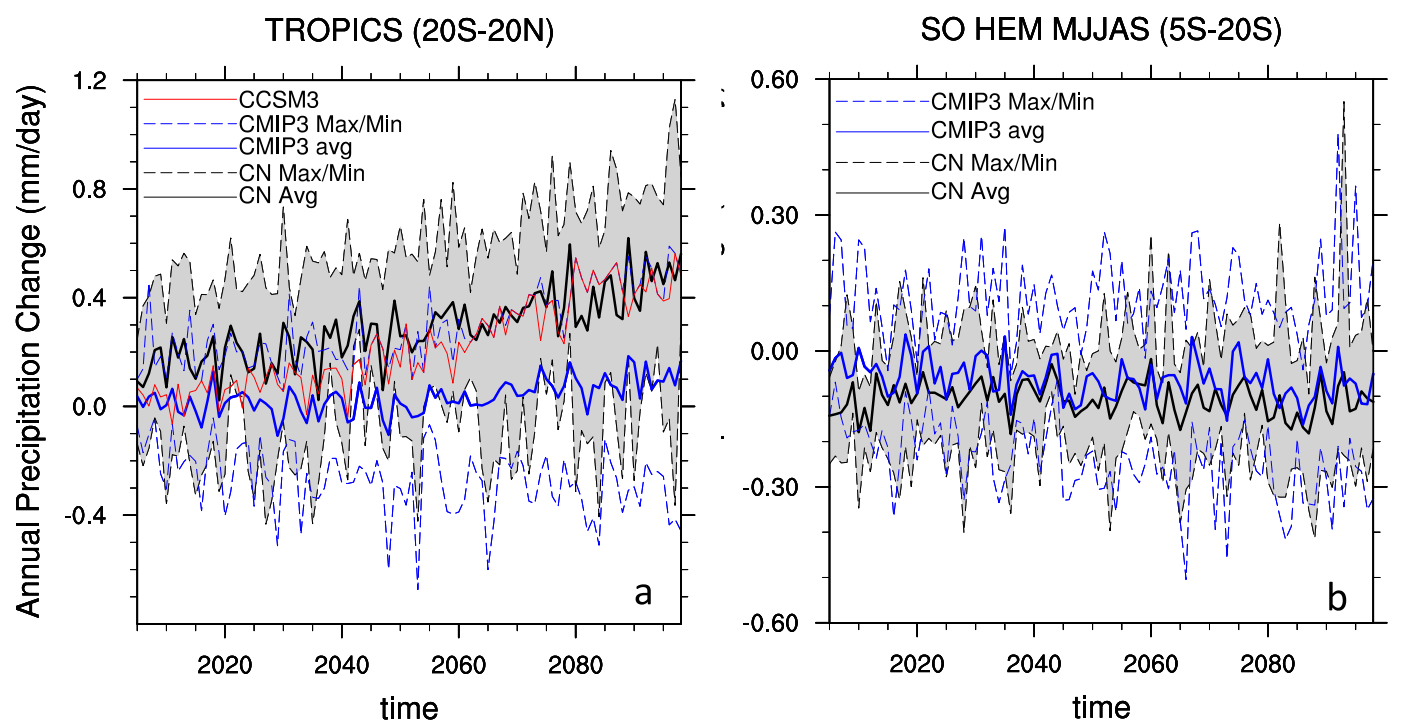

FIG. 10. Mean and range of precipitation change $\left(\mathrm{mm} \mathrm{day}^{-1}\right)$ for CAM-CLM-CN runs (black/gray) and CMIP3 runs (blue) for (a) annual average over tropical land areas $\left(20^{\circ} \mathrm{S}-20^{\circ} \mathrm{N}\right)$ and (b) Southern Hemisphere $\left(5^{\circ}-20^{\circ} \mathrm{S}\right)$ dry season (MJJAS). All differences are relative to 1970-99 means, computed for all models separately. Comparison of the solid blue and black lines shows the overall trend of the ensemble mean of the CMIP3 simulations vs the CAMCLM-CN simulations, respectively. 


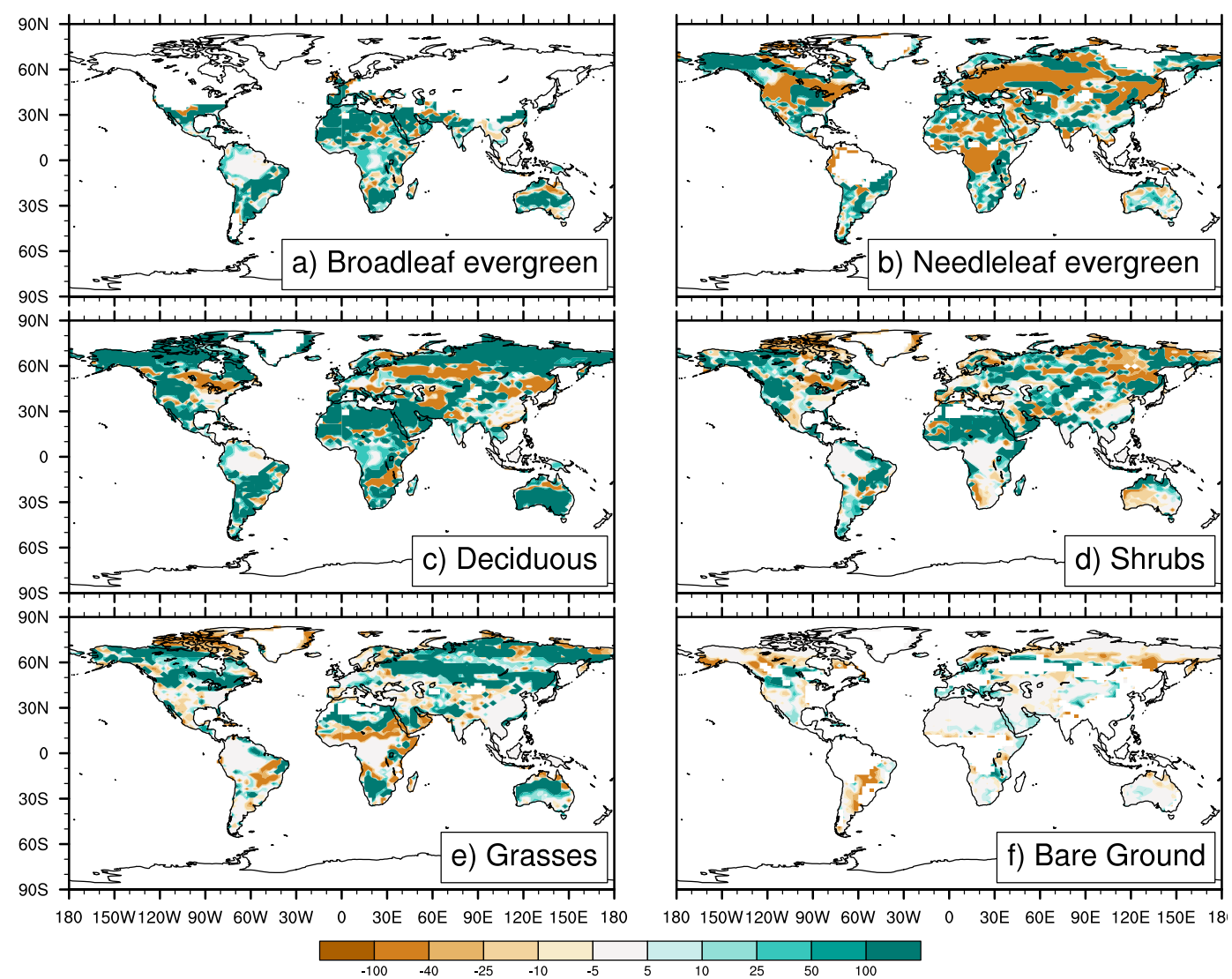

FIG. 11. Ensemble average changes in PFTs (\%) comparing the late twenty-first century (2070-99) and the twentieth century (1970-99) in CAM-CLM-CNDV simulations for (a) broadleaf evergreen trees, (b) needleleaf evergreen trees, (c) deciduous trees, (d) shrubs, (e) grasses, and (f) bare ground.

These mainly occur on the poleward edges of their twentieth-century modeled distribution (e.g., over southern Brazil and central Africa). Increases in deciduous trees also occur over western Africa. These increases in tropical broadleaf and deciduous trees correspond to decreases in grasses and temperate needleleaf evergreens. The latter occurs spuriously in the control run, and the future change is due to exceedance of the maximum temperature limit for the temperate needleleaf evergreen of $18.8^{\circ} \mathrm{C}$ (Levis et al. 2004). Despite the use of different SST patterns, the sign and spatial extent of the vegetation changes are consistent among the simulations (not shown). However, a few simulations do show small decreases in broadleaf evergreen and deciduous tree cover over the tropics $\left(20^{\circ} \mathrm{S}-20^{\circ} \mathrm{N}\right)$. We will explore these decreases in section $4 \mathrm{~b}(2)$.

As noted above, changes in mean vegetation cover over the tropics are fairly small; the fractional coverage of broadleaf evergreen trees and deciduous trees increases slightly from about $23 \%$ to $25.5 \%$ and from $21.5 \%$ to $23 \%$ (a percentage change of $11 \%$ and $7 \%$ of the original coverage, respectively) throughout the twenty-first century in the ensemble average. A few simulations show larger increases in broadleaf evergreen trees; these are the simulations forced by ECHAM5 and GISS. Interestingly, both of these models warm less in the eastern Pacific compared to their zonal mean warming (Fig. 2). Another model, CCSM3, also shows this departure but it does have more pronounced warming on the equator in the central Pacific. Lyon and Barnston (2005) showed that a robust relationship exists between the spatial extent of drought in the tropics and El Niño strength (based on Niño-3.4 SST anomalies); patterns that lack this characteristic are probably more likely to be wetter overall in the tropics. Indeed, the GISSdriven simulation has the largest trend in precipitation over land areas in the tropics $\left[0.52 \mathrm{~mm} \mathrm{day}^{-1}(95 \mathrm{yr})^{-1}\right]$, while ECHAM is tied for the third-largest increase $\left[0.40 \mathrm{~mm} \mathrm{day}^{-1}(95 \mathrm{yr})^{-1}\right]$. In contrast to these two simulations, in the HadCM3-driven simulation there are a few sharp declines in broadleaf evergreen cover and deciduous tree cover (Fig. 12, red line). Because each event is followed by a fast recovery, the changes in vegetation cover are not due to the slow 20 -yr climate 

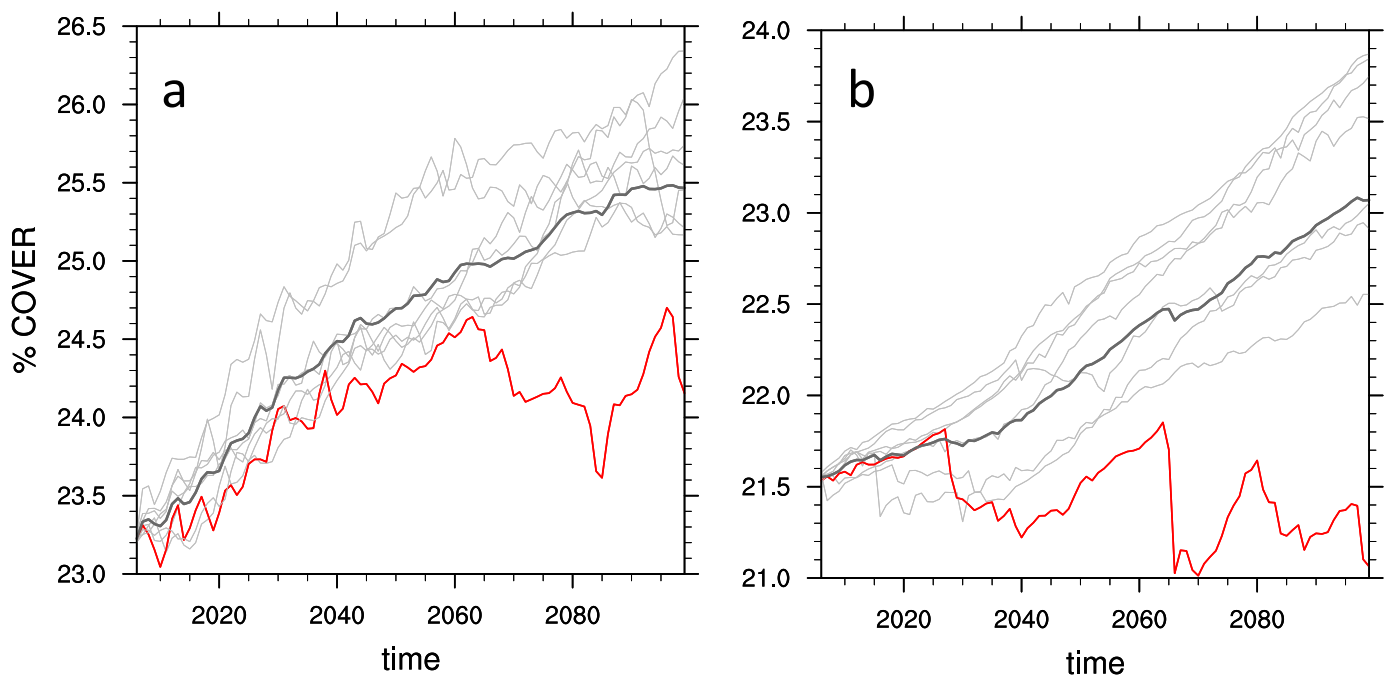

FIG. 12. Time series of vegetation cover (\%) in the tropics from 2006-2100 in CAM-CLM-CNDV simulations for (a) broadleaf evergreen trees and (b) deciduous trees. The twenty-first-century ensemble mean is shown in dark gray and individual ensemble members are shown in light gray. The HadCM3-driven CAM-CLM-CNDV ensemble member is in red.

envelope that can change PFT coverage in CAMCLM-CNDV. Instead, these temporary decreases in tree cover result from the activation of the fire algorithm in CLM (described above in section 2).

Figure 13a shows the fractional area burned over the tropics $\left(20^{\circ} \mathrm{S}-20^{\circ} \mathrm{N}\right)$. From 2005 to the end of the century, fractional area burned increases by about $30 \%$ in the ensemble mean, and several large events are noticeable in a few ensemble members, including the HadCM3-driven ensemble member, which is shown in red. These large events are also visible in a frequency histogram of fractional area burned (Fig. 13b), comparing the eight simulations in the last 40 years of the twenty-first century to the first 40 years of the twentyfirst century. Note that we compare the late twenty-first century to the early twenty-first century so that we can use all eight ensemble members so as to maintain the same number of values for each period. There is clearly an increase in the percentage of time a grid cell experiences a large fractional area burned (Fig. 13b). This relationship is maintained even when the HadCM3 ensemble member is removed (Fig. 13b, dashed lines). Over the tropics as a whole, fire season increases by about one week in the ensemble mean (7.21 days) over the twenty-first century (Fig. 14a).

These changes in dry season length are linked to an enhanced dry season in the future simulations, as indicated by the precipitation Hovmöller diagram in Fig. 15a. Figure 15a shows the precipitation climatology from the control simulation averaged over land areas over all longitudes in black contours. The annual cycle of precipitation clearly follows the solar annual cycle, reaching its maximum northward (southward) extension in the Northern (Southern) Hemisphere summer. The differences between the twenty-first and twentieth centuries (shaded) show an amplification of the annual cycle (i.e., wetter rainy seasons and drier dry seasons), a robust feature of precipitation change via the remote effect in future simulations (Tan et al. 2008; Seth et al. 2011, 2013). These decreases in winter precipitation are also apparent in Fig. 10b. These decreases in precipitation are reflected by changes in soil moisture, a variable which effectively integrates changes in precipitation, temperature, and evapotranspiration (Koster et al. 2004; Steiner et al. 2009). Recall that fire season length is controlled in part by near-surface soil moisture conditions in the fire module in CLM (Oleson et al. 2010). As a result of decreases in precipitation and increases in temperature (not shown), soil moisture decreases in the winter (dry) season of each hemisphere (Fig. 15b), leading to a lengthening of the fire season as shown in Fig. 14a.

\section{2) Tropical South AmericA}

Over tropical South America, fires with sufficient fractional area burned to remove vegetation (Fig. 16a, where the HadCM3-driven simulation is shown in red) occur in some of the simulations. Why do these changes happen in the simulations? First, large droughts that exceed observed $z$ scores emerge in the twenty-first century in several of the simulations. Figure 17a shows the area-averaged precipitation over tropical South America 

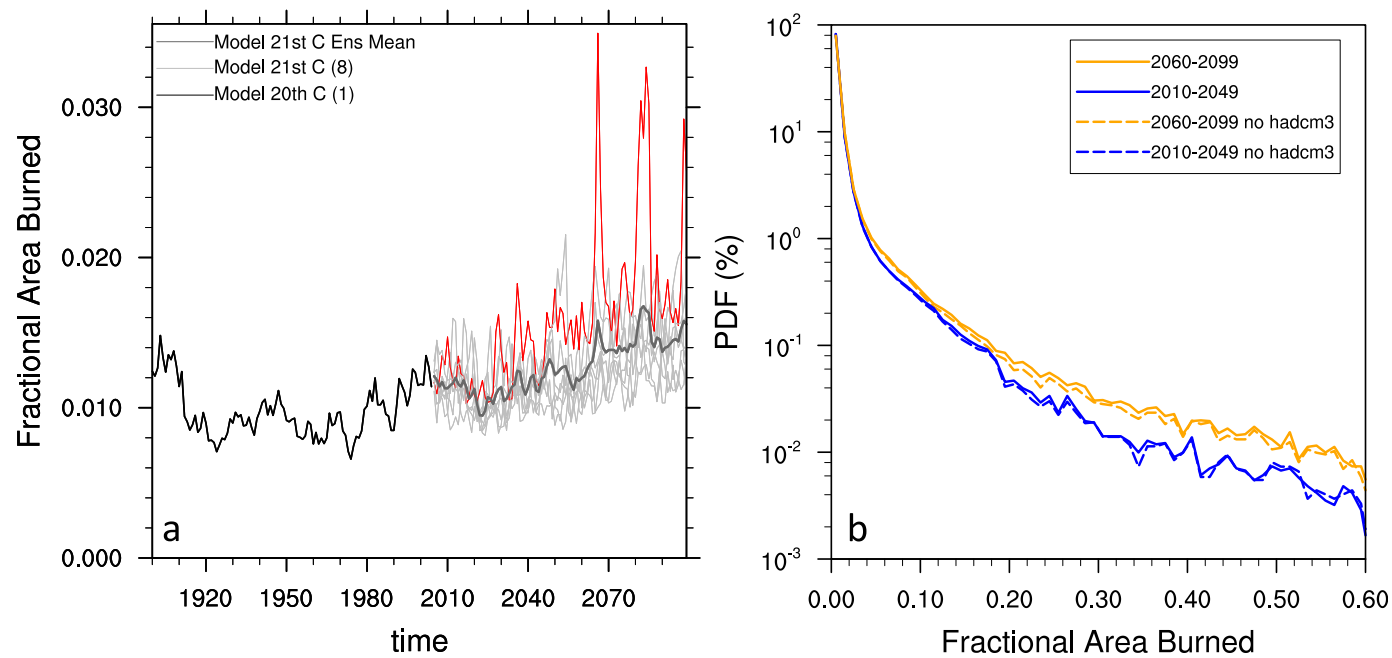

FIG. 13. (a) Fractional area burned (fraction) over the tropics $\left(20^{\circ} \mathrm{S}-20^{\circ} \mathrm{N}\right)$ for CAM-CLM-CNDV twentiethcentury control run (black), twenty-firs- century ensemble mean (dark gray), and individual ensemble members (light gray). The HadCM3-driven CAM-CLM-CNDV ensemble member is in red. (b) Frequency histogram of fractional area burned (fraction) for 2010-49 (blue) vs 2060-99 (yellow) considering all land grid points from $20^{\circ} \mathrm{S}-20^{\circ} \mathrm{N}$ for all ensemble members (solid lines) and excluding the HadCM3 forced ensemble member (dashed lines).

for the twentieth and twenty-first centuries. All are calculated relative to the twentieth-century simulation (except observations). Noticeable observed droughts occur over tropical South America, with precipitation anomalies that exceed -1 standard deviation. Severe droughts occur in the HadCM3-forced simulation (red line) that exceed -2 standard deviations from the mean.

These HadCM3 droughts are associated with positive SST anomalies over the tropical North Atlantic, less warm anomalies over the tropical South Atlantic, and El Niño-like conditions in the tropical Pacific, as shown by the instantaneous correlation between area-averaged precipitation over tropical South America and observed SSTs (Figs. 18a,b) for the CAMS-OPI observations and CAM-CLM-CN control run, respectively. Note that these droughts occur in the HadCM3-driven CAM-CLM-CN and CAM-CLM-CNDV simulations in the same years $(2065,2097$, and 2098; Figs. 18c-e),
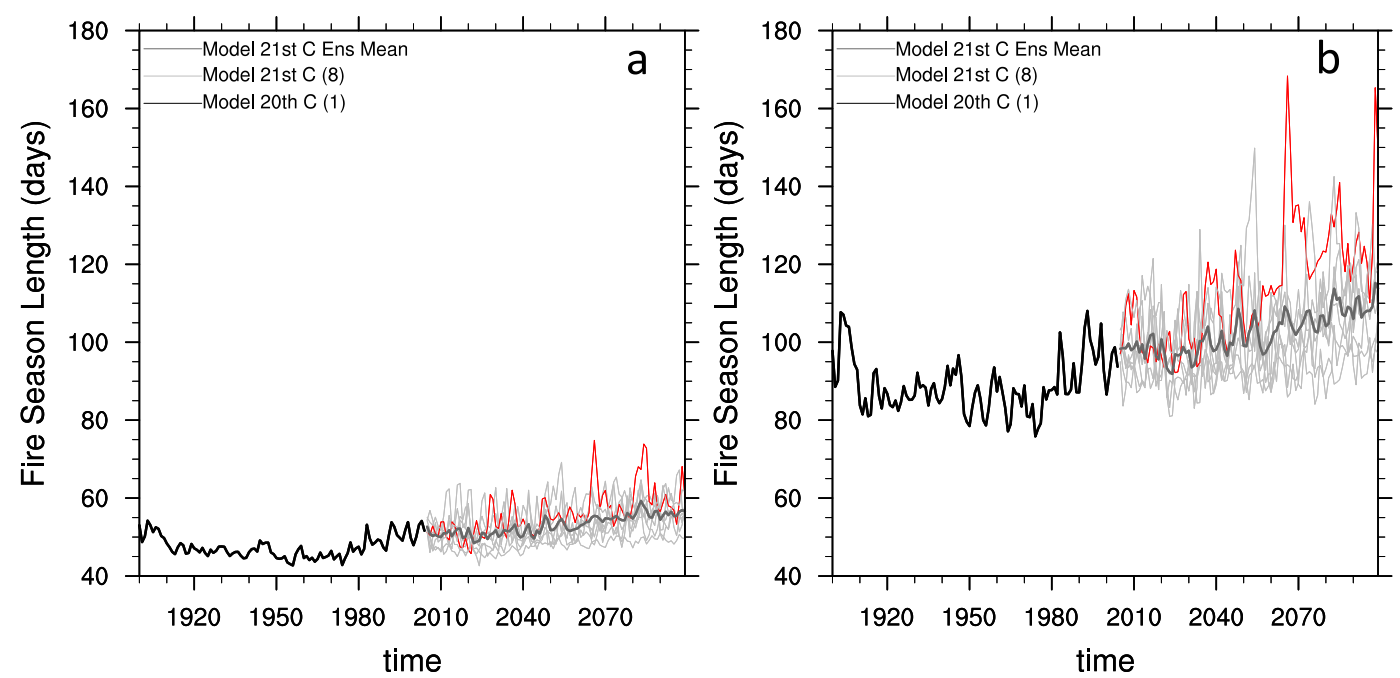

FIG. 14. Length of fire season (days) in the twentieth-century control run (black), twenty-first-century ensemble mean (dark gray), and individual ensemble members (light gray) in CAM-CLM-CNDV simulations over (a) the tropics $\left(20^{\circ} \mathrm{S}-20^{\circ} \mathrm{N}\right)$ and (b) tropical South America $\left(15^{\circ} \mathrm{S}-5^{\circ} \mathrm{N}, 70^{\circ}-45^{\circ} \mathrm{W}\right)$. In both panels, the HadCM3-driven CAM-CLM-CNDV ensemble member is shown in red. 

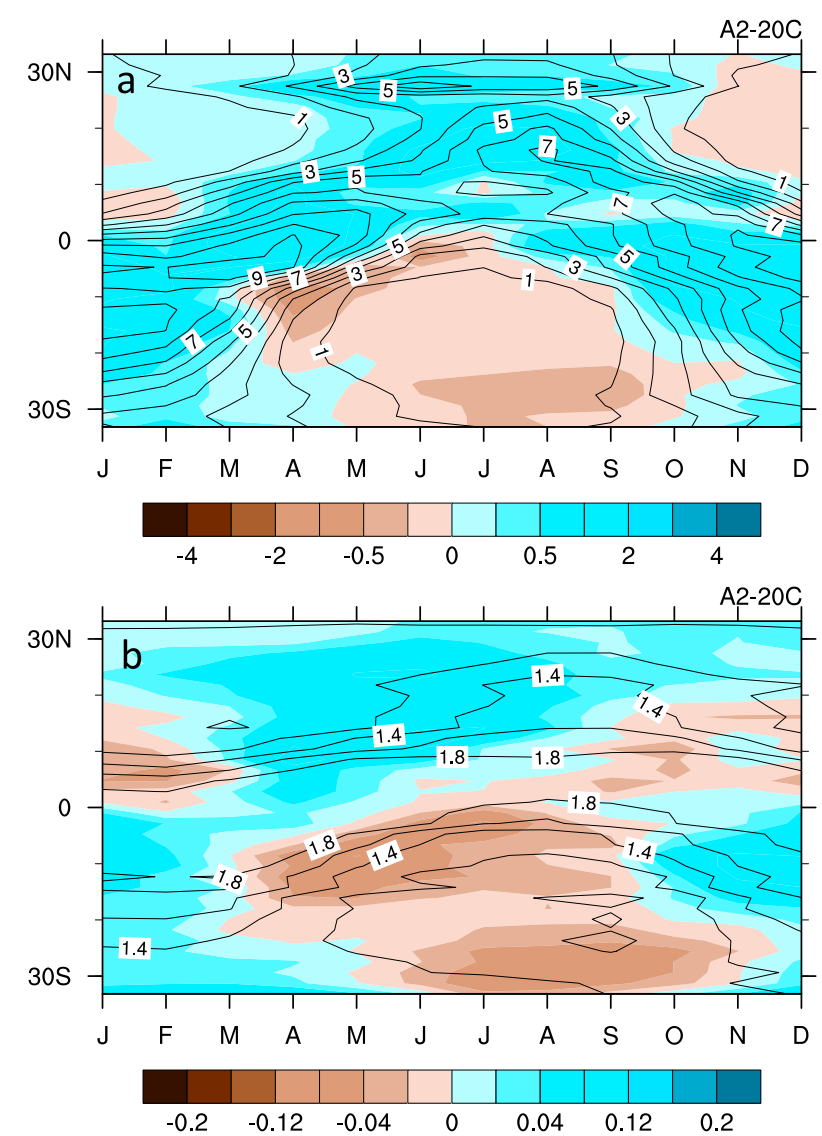

FIG. 15. (a) Hovmöller diagram of precipitation for the control simulation (black line; $\mathrm{mm} \mathrm{day}^{-1}$ ) and differences between the late twenty-first century (2070-99) and the twentieth century (1970-99) (shaded) in the CAM-CLM-CNDV simulations over land areas. (b) As in (a), but for the top $0.5 \mathrm{~m}$ soil moisture $\left(\mathrm{m}^{3} \mathrm{~m}^{-3}\right)$.

confirming that the SST anomalies are driving these events. Decreases in soil moisture contribute to the severity of these droughts. Despite an overall positive trend in annual average precipitation in the ensemble mean, soil moisture does not increase over the twentieth century over tropical South America (Fig. 17b). Consequently, fire season length increases in length by 2 weeks in the ensemble mean over the 95 -yr simulation period (Fig. 14b). These changes are particularly notable in the HadCM3-driven CAM-CLM-CNDV ensemble member, shown in red, which shows the large droughts (Fig. 17a), large decreases in soil moisture (Fig. 17b), and marked decreases in evapotranspiration (Fig. 17c).

Returning to why annual average precipitation increases in the future in our simulations-and why our simulations produce wetter futures than their CMIP3 parents-recall the local and remote effects discussed in the introduction. In the remote response, the rising heat content of the ocean and higher SSTs result in nearly

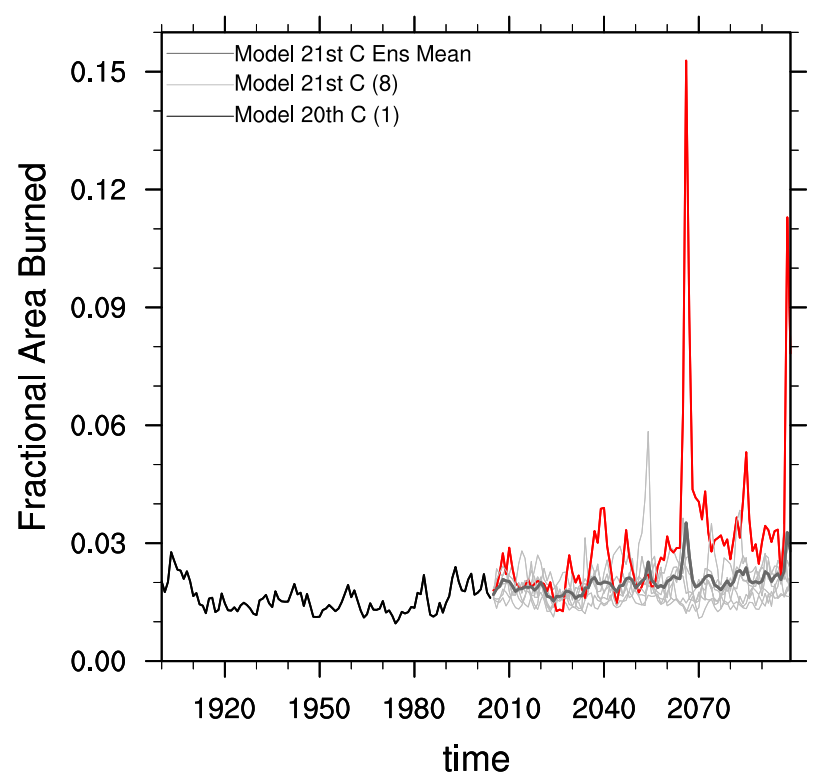

FIG. 16. Fractional area burned (fraction) over tropical South America $\left(5^{\circ} \mathrm{S}-5^{\circ} \mathrm{N}, 70^{\circ}-45^{\circ} \mathrm{W}\right)$ for CAM-CLM-CNDV twentiethcentury control run (black), twenty-first-century ensemble mean (dark gray), individual twenty-first century ensemble members (light gray), and HadCM3-driven ensemble member (red).

uniform warming in the upper troposphere (Sobel et al. 2001), increasing stability. Precipitation is reduced over tropical land areas where there is insufficient moist static energy to overcome this enhanced stability (Chou and Neelin 2004; Chou et al. 2009; Giannini 2010). In the local response, increases in net surface radiation lead to increases in evaporation and low-level moist static energy, driving increased precipitation and moisture convergence. In our simulations, the local effect appears to dominate since precipitation, net surface radiation, and evapotranspiration all increase on an annual average basis over tropical South America in nearly all ensemble members (Figs. 17a,c,d). Whether the remote or local effect is more important is likely linked to the strength of land surface-atmosphere interactions and therefore to the formulation of the land surface model, boundary layer, and convection parameterizations and deserves further exploration.

\section{Discussion and conclusions}

We have performed a series of experiments with CAM-CLM-CN and CAM-CLM-CNDV with SST warming patterns provided by eight of the CMIP3 projections under a medium-high emissions scenario. These experiments were designed to simulate a range of future climate-vegetation trajectories over the tropics. Because of the tendency of CAM-CLM-CN to favor the 

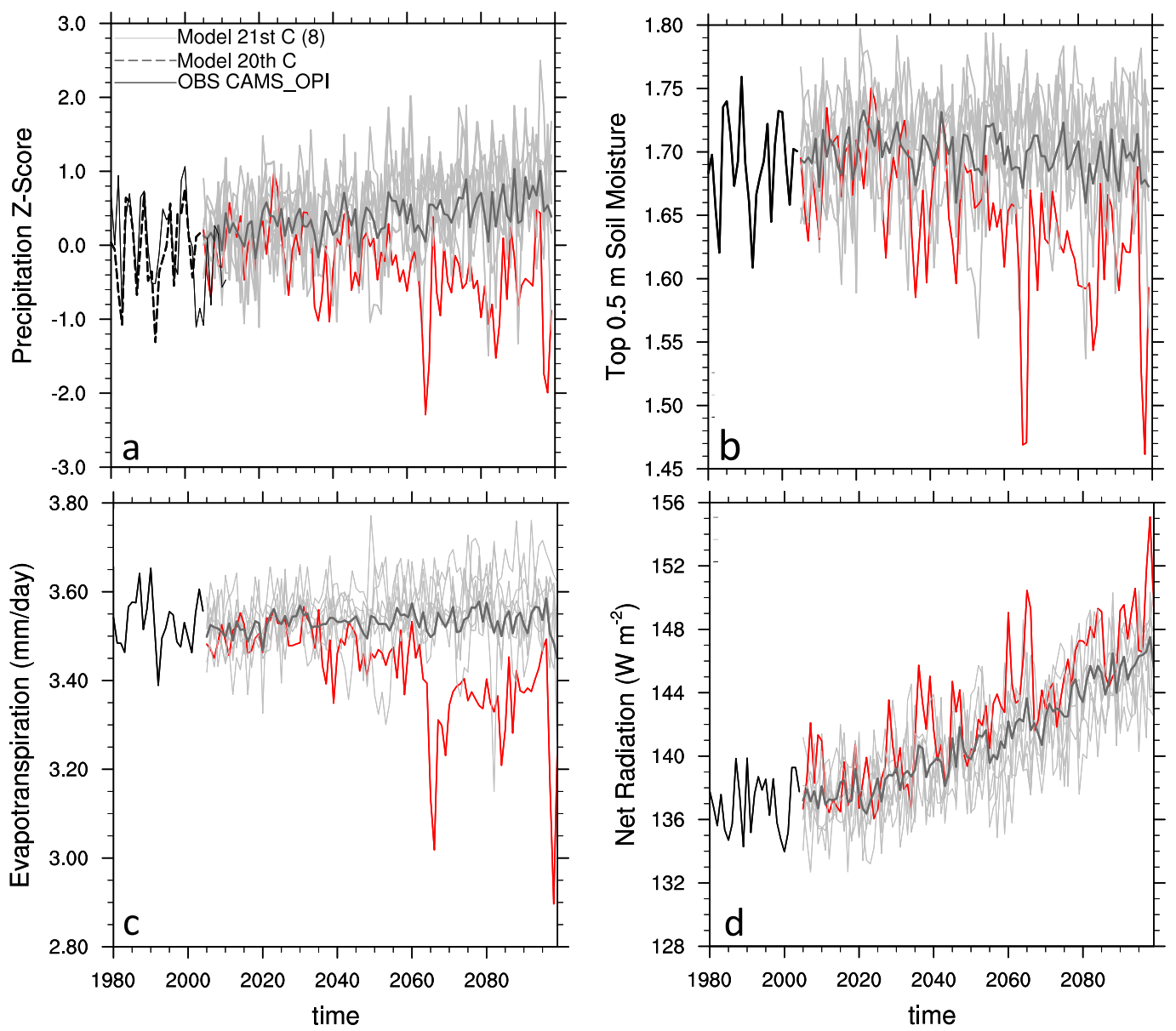

FIG. 17. Time series of surface climatic variables over tropical South America $\left(15^{\circ} \mathrm{S}-5^{\circ} \mathrm{N}, 70^{\circ}-45^{\circ} \mathrm{W}\right)$. (a) Precipitation $z$ scores (distance from mean in standard deviation units) for CAMS-OPI observations (black solid line), twentieth-century CAM-CLM-CNDV control run (black dashed line), twenty-first-century CAM-CLM-CNDV ensemble mean (dark gray), twenty-first-century individual ensemble members (light gray), and CAM-CLM-CNDV HadCM3 ensemble member (red). (b) Top 0.5-m soil moisture $\left(\mathrm{m}^{3} \mathrm{~m}^{-3}\right)$, (c) evapotranspiration $\left(\mathrm{mm} \mathrm{day}^{-1}\right)$, (d) surface net radiation $\left(\mathrm{W} \mathrm{m}^{-2}\right)$. (b)-(d) coloring as in (a), except no observations are shown.

local response to climate change-that is, changes in net radiation at the surface are translated to increased evaporation, net surface radiation, and precipitationoverall we did not see as large a spread in our projected future precipitation on an annual average basis as in the original CMIP3 archive that provided the SST boundary conditions. In other words, the different SST warming patterns do have an impact, but this effect is modulated by CAM-CLM-CN. However, our simulations did faithfully reproduce the drier dry season present in the CMIP3 simulations, which has important implications for vegetation change.

In our simulations with dynamic vegetation enabled, the fractional coverage of broadleaf evergreen trees and deciduous trees over the tropics increases from about $23 \%$ to $25.5 \%$ (a percentage difference of $11 \%$ ) and from $21.5 \%$ to $23 \%$ ( $7 \%$ increase), respectively, throughout the twenty-first century in the ensemble average. An exception is the HadCM3-driven experiment, which experiences several sharp declines and recoveries in tree cover over the tropics. As a result of the enhanced dry season, longer fire seasons and increases in fractional area burned are found over the tropics as a whole and in particular over tropical South America. These changes are evident even when the HadCM3-forced ensemble member is excluded. Our results echo many other studies of vegetation change over the region. Enhanced fire risk was also found in a study using the vegetationglobal-atmosphere-soil (VEGAS) model driven by output from 24 CMIP3 models (Cook et al. 2012). Similar to our results, Cook et al. (2012) found that a drier dry season (May-September) projected by the 


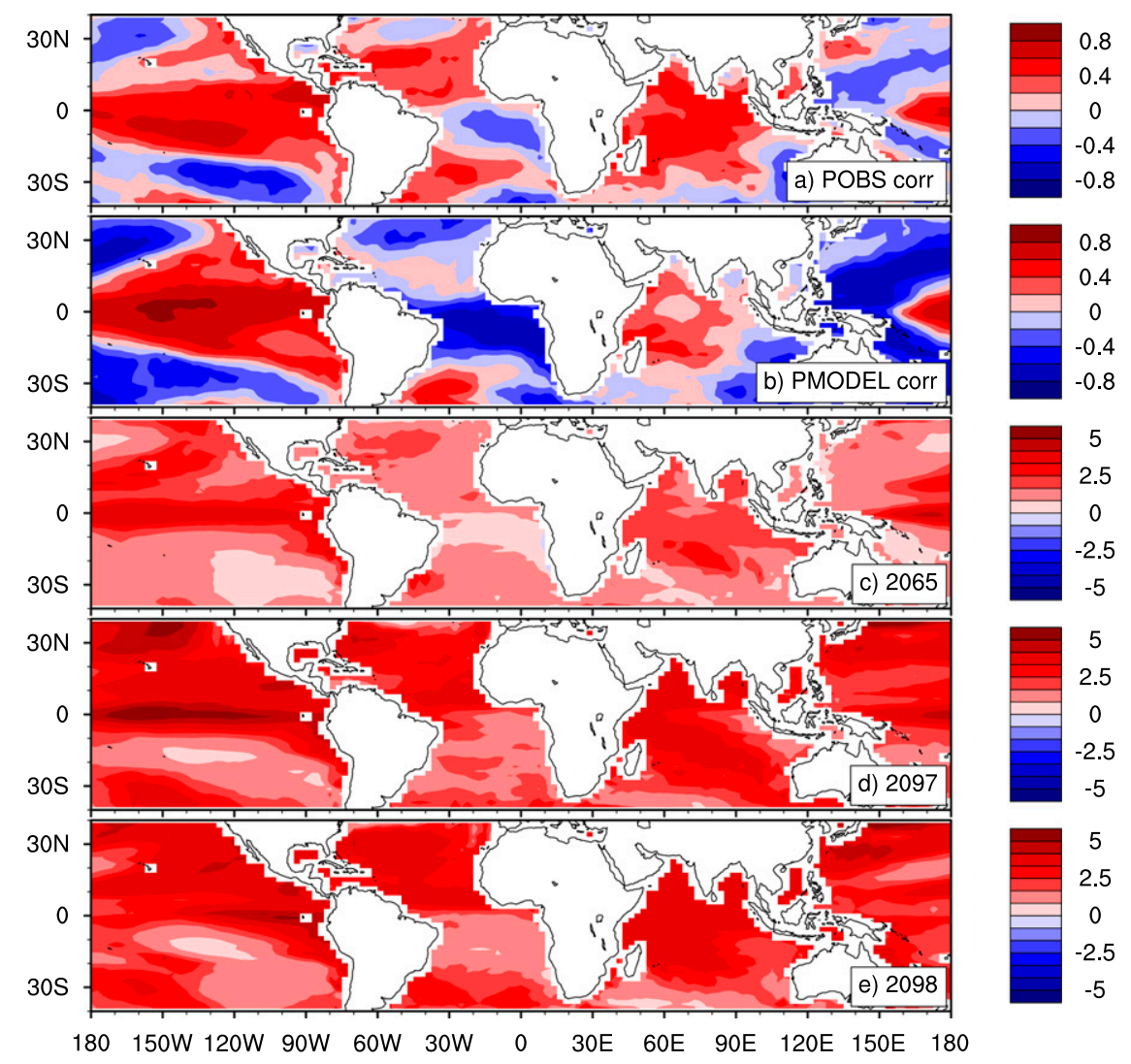

FIG. 18. Correlation between annual average observed SSTs $\left({ }^{\circ} \mathrm{C}\right)$ and precipitation $\left(\mathrm{mm} \mathrm{day}^{-1}\right)$ over tropical South America $\left(15^{\circ} \mathrm{S}-5^{\circ} \mathrm{N}, 70^{\circ}-45^{\circ} \mathrm{W}\right)$ showing (a) the correlation with CAMS-OPI observations and (b) the correlation with the CAM-CLM-CN control run precipitation from 1980 to 2004. Annual average SST anomalies $\left({ }^{\circ} \mathrm{C}\right)$ for (c) 2065, (d) 2097, and (e) 2098 from the HadCM3 coupled simulation compared to the 1970-99 HadCM3 average.

future scenario simulations leads to lower soil moisture and heightened fire risk in the Amazon. A recent study by Galbraith et al. (2010) suggests that DGVMs may in fact be underestimating the effects of soil moisture stress on vegetation based on field experiments where throughfall reaching the soil was reduced, leading to reduced biomass.

In the HadCM3-forced ensemble member, extreme drought occurrences over tropical South America associated with El Niño-like warming patterns in the Pacific and a meridional gradient in tropical Atlantic SSTs lead to fires that remove all vegetation cover over the eastern Amazon. While the other ensemble members show droughts and fire pulses as well, the HadCM3forced result appears to be unique in its extreme response. Modeling studies that use HadCM3 climate forcing typically find decreases in biomass due to the HadCM3 projected decrease in precipitation. For example, Sitch et al. (2008) found that five different dynamic vegetation models [hybrid land terrestrial ecosystem
(HyLand), ORCHIDEE, Sheffield-DVGM (SHE), TRIFFID, and LPJ] simulate decreases in vegetation carbon over Amazonia when the models are forced with the HadCM3 data. Huntingford et al. (2013) investigated how biomass stocks would change using the MOSES-TRIFFID land surface model forced with climate data from 22 of the CMIP3 models. Only in the HadCM3-forced simulation did biomass decrease over the tropical Americas. Malhi et al. (2009) calculated accumulated water stress from CMIP3 output for the twentieth and twenty-first centuries and found that there is a high probability of a more intense dry season in the future. Water stress increases over eastern Amazonia to the point where the region crosses a threshold to transition to savanna when the output from HadCM3 is used. Overall, their study predicts a climate over the eastern Amazon more suitable to seasonal forest, with the potential for enhanced fire risk.

The relative importance of the climate forcing and the physiological response is still uncertain. The 
similarities in responses across multiple DGVMs to the HadCM3 forcing suggest that the climate forcing is the most important factor when determining future trajectories of vegetation. However, if the fertilization response to $\mathrm{CO}_{2}$ is strong, biomass could increase despite precipitation decreases (Rammig et al. 2010). Substantial structural uncertainties remain in both our understanding of vegetation processes such as mortality events (McDowell et al. 2013) and how to model them (Adams et al. 2013). Our results and existing studies suggest that a large-scale reduction in forest cover is an unlikely but still possible event given the resemblance of recent droughts to CMIP3 HadCM3 projection (Marengo et al. 2008; Lewis et al. 2011). Similar to Malhi et al. (2009), we find that the risk is likely greatest in seasonally dry forests given the amplification of the precipitation annual cycle and drier springs simulated here in agreement with both CMIP3 (Seth et al. 2011) and CMIP5 (Seth et al. 2013) projections. This is in contrast to our results for the midlatitudes, where heat stress was the primary factor behind vegetation change (Jiang et al. 2013) in partial agreement with observed relationships (Williams et al. 2013).

Acknowledgments. We thank three anonymous reviewers for their comments, which greatly helped to improve the content and presentation of this manuscript. We thank A. T. Hoang and S. Levis for their help with obtaining CMIP3 data and CLM4 initial data files. We thank S. Levis, D. Lawrence, and A. Giannini for helpful discussions. Los Alamos National Laboratory LDRD and DOE Office of Science (BER) provided funding for this project. The National Center for Atmospheric Research (NCAR) is operated by the University Corporation for Atmospheric Research under sponsorship of the National Science Foundation.

\section{REFERENCES}

Adams, H. D., A. P. Williams, C. Xu, S. A. Rauscher, X. Jiang, and N. G. McDowell, 2013: Empirical and process-based approaches to climate-induced forest mortality models. Front. Plant Sci., 4, 438, doi:10.3389/fpls.2013.00438.

Allen, C. D., and Coauthors, 2010: A global overview of drought and heat-induced tree mortality reveals emerging climate change risks for forests. For. Ecol. Manage., 259, 660-684, doi:10.1016/j.foreco.2009.09.001.

Ballantyne, A. P., C. B. Alden, J. B. Miller, P. P. Tans, and J. W. C. White, 2012: Increase in observed net carbon dioxide uptake by land and oceans during the past 50 years. Nature, $\mathbf{4 8 8}, 70$ 72, doi:10.1038/nature11299.

Biasutti, M., and A. H. Sobel, 2009: Delayed Sahel rainfall and global seasonal cycle in a warmer climate. Geophys. Res. Lett, 36, L23707, doi:10.1029/2009GL041303.
Chou, C., and J. D. Neelin, 2004: Mechanisms of global warming impacts on regional tropical precipitation. J. Climate, 17, 2688-2701, doi:10.1175/1520-0442(2004)017<2688: MOGWIO $>2.0 . \mathrm{CO} ; 2$.

- — _ C.-A. Chen, and J.-Y. Tu, 2009: Evaluating the "richget-richer" mechanism in tropical precipitation change under global warming. J. Climate, 22, 1982-2005, doi:10.1175/ 2008JCLI2471.1.

Cook, B., N. Zeng, and J.-H. Yoon, 2012: Will Amazonia dry out? Magnitude and causes of change from IPCC climate model projections. Earth Interact., 16, 1-27, doi:10.1175/ 2011EI398.1.

Cox, P. M., R. A. Betts, C. D. Jones, S. A. Spall, and I. J. Totterdell, 2000: Acceleration of global warming due to carbon-cycle feedbacks in a coupled climate model. Nature, 408, 184-187, doi:10.1038/35041539.

,-- M. Collins, P. P. Harris, C. Huntingford, and C. D. Jones, 2004: Amazonian forest dieback under climate-carbon cycle projections for the 21st century. Theor. Appl. Climatol., 78, 137-156, doi:10.1007/s00704-004-0049-4.

Galbraith, D., P. Levy, S. Sitch, C. Huntingford, P. Cox, M. Williams, and P. Meir, 2010: Multiple mechanisms of Amazonian forest biomass losses in three dynamic global vegetation models under climate change. New Phytol., 187, 647-665, doi:10.1111/j.1469-8137.2010.03350.x.

Gent, P. R., and Coauthors, 2011: The Community Climate System Model version 4. J. Climate, 24, 4973-4991, doi:10.1175/ 2011JCLI4083.1.

Giannini, A., 2010: Mechanisms of climate change in the semiarid African Sahel: The local view. J. Climate, 23, 743-756, doi:10.1175/2009JCLI3123.1.

Gotangco Castillo, C. K., S. Levis, and P. Thornton, 2012: Evaluation of the new CNDV option of the Community Land Model: Effects of dynamic vegetation and interactive nitrogen on CLM4 means and variability. J. Climate, 25, 3702-3714, doi:10.1175/JCLI-D-11-00372.1.

Harris, P. P., C. Huntingford, and P. M. Cox, 2008: Amazon basin climate under global warming: The role of the sea surface temperature. Philos. Trans. Roy. Soc. London, 363B, 17531759, doi:10.1098/rstb.2007.0037.

Huang, P., S.-P. Xie, K. Hu, G. Huang, and R. Huang, 2013: Patterns of the seasonal response of tropical rainfall to global warming. Nat. Geosci., 6, 357-361, doi:10.1038/ngeo1792.

Huntingford, C., and Coauthors, 2013: Simulated resilience of tropical rainforests to $\mathrm{CO}_{2}$-induced climate change. Nat. Geosci., 6, 268-273, doi:10.1038/ngeo1741.

Hurrell, J. W., J. J. Hack, D. Shea, J. M. Caron, and J. Rosinski, 2008: A new sea surface temperature and sea ice boundary dataset for the Community Atmosphere Model. J. Climate, 21, 5145-5153, doi:10.1175/2008JCLI2292.1.

IPCC, 2000: Special Report on Emissions Scenarios. Cambridge University Press, 570 pp. [Available online at http://www.ipcc. ch/ipccreports/sres/emission/index.php?idp $=0$.]

Janowiak, J. E., and P. Xie, 1999: CAMS-OPI: A global satelliterain gauge merged product for real-time precipitation monitoring applications. J. Climate, 12, 3335-3342, doi:10.1175/ 1520-0442(1999)012<3335:COAGSR $>2.0 . \mathrm{CO} ; 2$.

Jiang, X., and Coauthors, 2013: Projected future changes in vegetation in western North America in the twenty-first century. J. Climate, 26, 3671-3687, doi:10.1175/JCLI-D-12-00430.1.

Koster, R. D., and Coauthors, 2004: Regions of strong coupling between soil moisture and precipitation. Science, 305, 11381140, doi:10.1126/science.1100217. 
Lamarque, J. F., and Coauthors, 2010: Historical (1850-2000) gridded anthropogenic and biomass burning emissions of reactive gases and aerosols: Methodology and application. Atmos. Chem. Phys., 10, 7017-7039, doi:10.5194/acp-10-7017-2010.

Lawrence, D. M., and Coauthors, 2011: Parameterization improvements and functional and structural advances in version 4 of the Community Land Model. J. Adv. Model. Earth Syst., 3, M03001, doi:10.1029/2011MS000045.

Leloup, J., and A. Clement, 2009: Why is there a minimum in projected warming in the tropical North Atlantic Ocean? Geophys. Res. Lett., 36, L14802, doi:10.1029/ 2009GL038609.

Levis, S., G. B. M. Vertenstein, and K. Oleson, 2004: The Community Land Model's Dynamic Global Vegetation Model (CLM-DGVM): Technical description and user's guide. NCAR Tech. Note NCAR/TN-459+IA, 50 pp. [Available online at http://www.cgd.ucar.edu/tss/clm/distribution/clm3.0/ DGVMDoc/TN-459+IA.pdf.]

Lewis, S. L., P. M. Brando, O. L. Phillips, G. M. F. van der Heijden, and D. Nepstad, 2011: The 2010 Amazon drought. Science, 331, 554, doi:10.1126/science. 1200807 .

Li, F., X. D. Zeng, and S. Levis, 2012: A process-based fire parameterization of intermediate complexity in a dynamic global vegetation model. Biogeosci. Discuss., 9, 3233-3287, doi:10.5194/ bgd-9-3233-2012.

Li, W., R. Fu, and R. E. Dickinson, 2006: Rainfall and its seasonality over the Amazon in the 21st century as assessed by the coupled models for the IPCC AR4. J. Geophys. Res., 111, D02111, doi:10.1029/2005JD006355.

Lyon, B., and A. G. Barnston, 2005: ENSO and the spatial extent of interannual precipitation extremes in tropical land areas. J. Climate, 18, 5095-5109, doi:10.1175/JCLI3598.1.

Ma, J., and S.-P. Xie, 2013: Regional patterns of sea surface temperature change: A source of uncertainty in future projections of precipitation and atmospheric circulation. J. Climate, 26, 2482-2501, doi:10.1175/JCLI-D-12-00283.1.

Malhi, Y., and Coauthors, 2009: Exploring the likelihood and mechanism of a climate-change-induced dieback of the Amazon rainforest. Proc. Natl. Acad. Sci. USA, 106, 20610 20 615, doi:10.1073/pnas.0804619106.

Marengo, J., and Coauthors, 2008: The drought of Amazonia in 2005. J. Climate, 21, 495-516, doi:10.1175/2007JCLI1600.1.

McDowell, N. G., and Coauthors, 2013: Evaluating theories of drought-induced vegetation mortality using a multimodel experiment framework. New Phytol., 200, 304-321, doi:10.1111/ nph. 12465 .

Meehl, G. A., C. Covey, K. E. Taylor, T. Delworth, R. J. Stouffer, M. Latif, B. McAvaney, and J. F. B. Mitchell, 2007: The WCRP CMIP3 multimodel dataset: A new era in climate change research. Bull. Amer. Meteor. Soc., 88, 1383-1394, doi:10.1175/BAMS-88-9-1383.

Neale, R. B., and Coauthors, 2010: Description of the NCAR Community Atmosphere Model (CAM 4.0). NCAR Tech. Note NCAR/TN-485+STR, 212 pp. [Available online at http:// www.cesm.ucar.edu/models/ccsm4.0/cam/docs/description/ cam4_desc.pdf.]

Notaro, M., S. Vavrus, and Z. Liu, 2007: Global vegetation and climate change due to future increases in $\mathrm{CO}_{2}$ as projected by a fully coupled model with dynamic vegetation. J. Climate, 20, 70-90, doi:10.1175/JCLI3989.1.

Oleson, K. W., and Coauthors, 2010: Technical description of version 4.0 of the Community Land Model (CLM). NCAR Tech. Note NCAR/TN-478+STR, 257 pp. [Available online at http://www.cesm.ucar.edu/models/ccsm4.0/clm/CLM4 Tech_Note.pdf.]

Qian, T., A. Dai, K. E. Trenberth, and K. W. Oleson, 2006: Simulation of global land surface conditions from 1948 to 2004. Part I: Forcing data and evaluations. J. Hydrometeor., 7, 953975, doi:10.1175/JHM540.1.

Rammig, A., and Coauthors, 2010: Estimating the risk of Amazonian forest dieback. New Phytol., 187, 694-706, doi:10.1111/ j.1469-8137.2010.03318.x.

Rauscher, S. A., F. Giorgi, N. Diffenbaugh, and A. Seth, 2008: Extension and intensification of the Meso-American midsummer drought in the twenty-first century. Climate Dyn., 31, 551-571, doi:10.1007/s00382-007-0359-1.

— , F. Kucharski, and D. B. Enfield, 2011: The role of regional SST warming variations in the drying of Meso-America in future climate projections. J. Climate, 24, 2003-2016, doi:10.1175/ 2010JCLI3536.1.

Seth, A., M. Rojas, and S. Rauscher, 2010: CMIP3 projected changes in the annual cycle of the South American monsoon. Climatic Change, 98, 331-357, doi:10.1007/s10584-009-9736-6.

_ S. Rauscher, M. Rojas, A. Giannini, and S. Camargo, 2011: Enhanced spring convective barrier for monsoons in a warmer world? Climatic Change, 104, 403-414, doi:10.1007/ s10584-010-9973-8.

,-- _ M. Biasutti, A. Giannini, S. J. Camargo, and M. Rojas, 2013: CMIP5 projected changes in the annual cycle of precipitation in monsoon regions. J. Climate, 26, 7328-7351, doi:10.1175/JCLI-D-12-00726.1.

Sitch, S., and Coauthors, 2003: Evaluation of ecosystem dynamics, plant geography and terrestrial carbon cycling in the LPJ dynamic global vegetation model. Global Change Biol., 9, 161-185, doi:10.1046/j.1365-2486.2003.00569.x.

— , and Coauthors, 2008: Evaluation of the terrestrial carbon cycle, future plant geography and climate-carbon cycle feedbacks using five dynamic global vegetation models (DGVMs). Global Change Biol., 14, 2015-2039, doi:10.1111/ j.1365-2486.2008.01626.x.

Sobel, A. H., J. Nilsson, and L. M. Polvani, 2001: The weak temperature gradient approximation and balanced tropical moisture waves. J. Atmos. Sci., 58, 3650-3665, doi:10.1175/ 1520-0469(2001)058<3650:TWTGAA $>2.0 . \mathrm{CO} ; 2$.

Steiner, A. L., J. S. Pal, S. A. Rauscher, J. L. Bell, N. S. Diffenbaugh, A. Boone, L. C. Sloan, and F. Giorgi, 2009: Land surface coupling in regional climate simulations of the West African monsoon. Climate Dyn., 33, 869-892, doi:10.1007/ s00382-009-0543-6.

Tan, P.-H., C. Chou, and J.-Y. Tu, 2008: Mechanisms of global warming impacts on robustness of tropical precipitation asymmetry. J. Climate, 21, 5585-5602, doi:10.1175/ 2008JCLI2154.1.

Thonicke, K., S. Venevsky, S. Sitch, and W. Cramer, 2001: The role of fire disturbance for global vegetation dynamics: Coupling fire into a dynamic global vegetation model. Global Ecol. Biogeogr., 10, 661-677, doi:10.1046/ j.1466-822X.2001.00175.x.

Thornton, P. E., J.-F. Lamarque, N. A. Rosenbloom, and N. M. Mahowald, 2007: Influence of carbon-nitrogen cycle coupling on land model response to $\mathrm{CO}_{2}$ fertilization and climate variability. Global Biogeochem. Cycles, 21, GB4018, doi:10.1029/ 2006GB002868.

Williams, A. P., and Coauthors, 2013: Temperature as a potent driver of regional forest drought stress and tree mortality. Nat. Climate Change, 3, 292-297, doi:10.1038/nclimate1693. 
Willmott, C. J., and K. Matsuura, 1995: Smart interpolation of annually averaged air temperature in the United States. J. Appl. Meteor., 34, 2577-2586, doi:10.1175/1520-0450(1995)034<2577: SIOAAA $>2.0 . \mathrm{CO} ; 2$.

and - 2001: Terrestrial air temperature and precipitation: Monthly and annual time series (1950-1999). [Available online at http://climate.geog.udel.edu/ climate/html_pages/ README.ghon_ts2.html.]
Xie, P., and P. A. Arkin, 1996: Analyses of global monthly precipitation using gauge observations, satellite estimates, and numerical model predictions. J. Climate, 9, 840-858, doi:10.1175/ 1520-0442(1996)009<0840:AOGMPU>2.0.CO;2.

Xie, S.-P., C. Deser, G. A. Vecchi, J. Ma, H. Teng, and A. T. Wittenberg, 2010: Global warming pattern formation: Sea surface temperature and rainfall. J. Climate, 23, 966-986, doi:10.1175/2009JCLI3329.1. 